OPEN ACCESS

Edited by:

Hans-Henning Kunz,

Washington State University, USA

Reviewed by:

Xia Wu,

University of Washington, USA

Sujith Puthiyaveetil,

Purdue University, USA

*Correspondence:

Radek Kaňa

kana@alga.cz

Dedication:

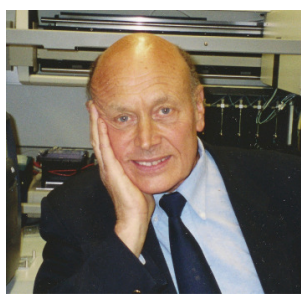

Dedicated to the pioneering research of James (Jim) Barber on many aspects of photosynthesis including

the electrostatic properties of the chloroplast thylakoid membrane, and who received the 2016

Communication Award of the

International Society of

Photosynthesis Research (ISPR).

Specialty section: This article was submitted to Plant Physiology, a section of the journa

Frontiers in Plant Science

Received: 08 September 2016 Accepted: 23 November 2016

Published: 16 December 2016

Citation:

Kaňa R and Govindjee (2016) Role of lons in the Regulation of Light-Harvesting

Front. Plant Sci. 7:1849. doi: 10.3389/fpls.2016.01849

\section{Role of lons in the Regulation of Light-Harvesting}

\author{
Radek Kaňa ${ }^{1,2 *}$ and Govindjee ${ }^{3}$
}

${ }^{1}$ Institute of Microbiology, Academy of Sciences of the Czechia, Treboň, Czechia, ${ }^{2}$ Faculty of Science, Institute of Chemistry and Biochemistry, University of South Bohemia, České Budëjovice, Czechia, ${ }^{3}$ Center of Biophysics and Quantitative Biology, Department of Biochemistry, Department of Plant Biology, University of Illinois at Urbana-Champaign, Urbana, IL, USA

Regulation of photosynthetic light harvesting in the thylakoids is one of the major key factors affecting the efficiency of photosynthesis. Thylakoid membrane is negatively charged and influences both the structure and the function of the primarily photosynthetic reactions through its electrical double layer (EDL). Further, there is a heterogeneous organization of soluble ions $\left(\mathrm{K}^{+}, \mathrm{Mg}^{2+}, \mathrm{Cl}^{-}\right)$attached to the thylakoid membrane that, together with fixed charges (negatively charged amino acids, lipids), provides an electrical field. The EDL is affected by the valence of the ions and interferes with the regulation of "state transitions," protein interactions, and excitation energy "spillover" from Photosystem II to Photosystem I. These effects are reflected in changes in the intensity of chlorophyll a fluorescence, which is also a measure of photoprotective non-photochemical quenching (NPQ) of the excited state of chlorophyll a. A triggering of NPQ proceeds via lumen acidification that is coupled to the export of positive counter-ions $\left(\mathrm{Mg}^{2+}, \mathrm{K}^{+}\right)$to the stroma or/and negative ions (e.g., $\left.\mathrm{Cl}^{-}\right)$into the lumen. The effect of protons and anions in the lumen and of the cations $\left(\mathrm{Mg}^{2+}, \mathrm{K}^{+}\right)$in the stroma are, thus, functionally tightly interconnected. In this review, we discuss the consequences of the model of EDL, proposed by Barber (1980b) Biochim Biophys Acta 594:253-308) in light of light-harvesting regulation. Further, we explain differences between electrostatic screening and neutralization, and we emphasize the opposite effect of monovalent $\left(\mathrm{K}^{+}\right)$ and divalent $\left(\mathrm{Mg}^{2+}\right)$ ions on light-harvesting and on "screening" of the negative charges on the thylakoid membrane; this effect needs to be incorporated in all future models of photosynthetic regulation by ion channels and transporters.

Keywords: ions, non-photochemical quenching, state transitions, light-harvesting protein complexes, photosynthesis, photoprotection

\section{INTRODUCTION}

Thylakoids and other energy transducing membranes produce ATP employing transmembrane electrochemical gradient of protons; see original papers proving this concept (Junge and Witt, 1968; Junge et al., 1968, 1970; Schliephake et al., 1968) as well as selected reviews (Junge, 2004, 2013; Junge and Nelson, 2015). The proton gradient is formed by proton pumps and is coupled with

Abbreviations: Chl, chlorophyll; DCMU, 3-(3,4-dichlorophenyl)-1,1-dimethylurea; EDL, electrical double layer; PS I (II), photosystems I (II); TM, thylakoid membrane 
light-driven electron transport. Peter Mitchell explained the entire process by his chemiosmotic theory (Mitchell, 1961, 1966), for which he received the 1978 Nobel Prize in Chemistry. In this theory, the unidirectional electrochemical gradient of protons across the membranes, the "proton motive force" ( $p m f)$, is used for ATP synthesis; this pmf (Equation 1) consists of two components: electrical ( $\Delta \psi$-the membrane potential) and chemical ( $\Delta \mathrm{pH}$-proton gradient across membrane), both of which can be used for ATP synthesis (cf. Figure 1):

$$
p m f(m V)=\Delta \psi+\frac{2.3 R T}{F} \Delta p H
$$

where, $\mathrm{R}$ is the universal gas constant, $\mathrm{F}$ the Faraday constant, and $\mathrm{T}$ the temperature, in Kelvin (equivalent to temperature in Celsius plus 273.15). In mitochondria, $\Delta \psi$ predominates (Mitchell, 1966), whereas in chloroplasts, $\Delta \mathrm{pH}$ is the major component (Ort and Melandri, 1982). The $\Delta \mathrm{pH}$ across the membranes is used not only for making ATP from ADP and Pi, but is also known to control the efficiency of light harvesting and photoprotection (Wraight and Crofts, 1970; Briantais et al., 1979) and regulates electron transport and ATP synthesis (Tikhonov, 2013).

There is still no clear consensus about the precise division of steady-state thylakoid proton motive force between the $\Delta \mathrm{pH}$ and the electric field gradient $(\Delta \psi)$. Based on measurements of electrochromic shift, there are irreconcilable findings indicating a partial (Cruz et al., 2001), or a total collapse of $\Delta \psi$ (Johnson and Ruban, 2014) under steady state conditions. To resolve this discrepancy, we need to know the extent of particular counterion transport (i.e., $\mathrm{K}^{+}, \mathrm{Cl}^{-}, \mathrm{Mg}^{2+}$ ) in the steady state (see discussion Kramer et al., 1999; Cruz et al., 2001) as the transport of both protons and ions affect the partitioning of pmf into $\Delta \psi$ and $\Delta \mathrm{pH}$ (Kramer et al., 2004; Lyu and Lazár, 2017). The pmf partitioning is an important factor indirectly regulating the light-harvesting: (1) by lumen acidification that triggers nonphotochemical quenching (see Horton, 2014); (2) by changes in ion (mostly $\mathrm{Mg}^{2+}$ ) concentration in the stroma, which affects excitation energy redistribution between the two photosystems, during state transitions (see Barber, 1980b). Importantly, the concentration of ions and the presence of electrical fields across

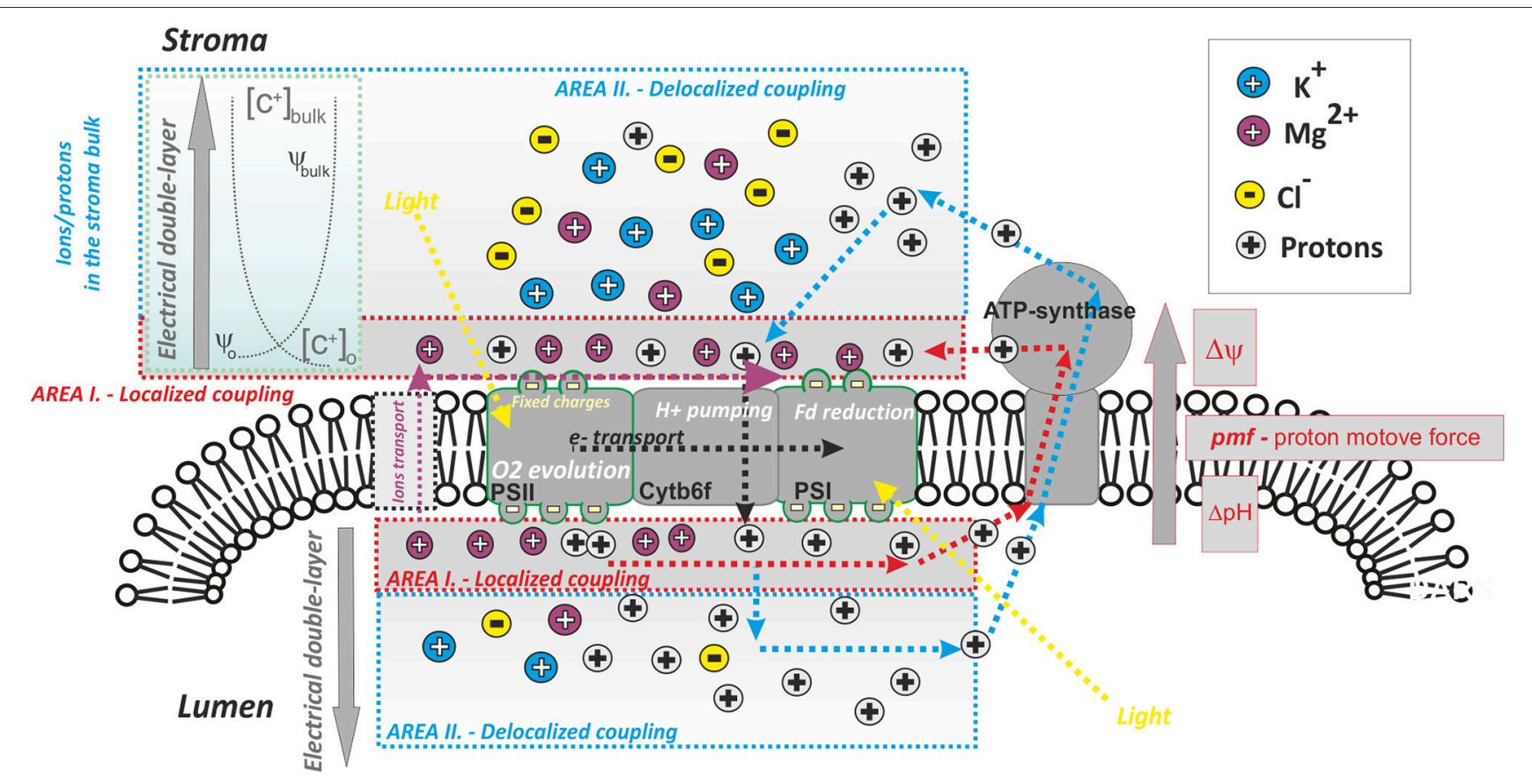

FIGURE 1 | A simplified scheme of photophosphorylation in photosynthesis: role of proton and ion heterogeneity. ATP synthase uses proton gradient across the thylakoid membrane; the proton transport across the thylakoid is coupled to light-driven electron transport (dotted black lines). The proton gradient forms electrochemical gradient of protons [pmf-proton motive force, which includes $\Delta \psi$ (the membrane potential component) and $\Delta \mathrm{pH}$ (proton gradient component; see Equation 1)]; pmf is the driving force for ATP synthesis. The most accepted view of photophosphorylation is: "delocalized phosphorylation" - equilibrated concentration of protons in the bulk (in the stroma/lumen) is used (original Mitchell theory-dashed blue lines, see Mitchell, 1966). A second less accepted view is that of "localized phosphorylation" (dashed red lines, see Mulkidjanian et al., 2006): protons from the local domains in lumen/stroma that are in the close vicinity of membrane (see Area I) are involved in ATP synthesis (Dilley, 2004). Localized protons interact with ions attached to fixed membrane charges, mostly Mg $2+$ (note: $\mathrm{K}^{+}$ and $\mathrm{Cl}^{-}$are more abundant in the thylakoid stroma/lumen bulk, see Barber, 1980b). The distribution of the dominant ions ( $\left.\mathrm{K}^{+}, \mathrm{Mg}^{2+}, \mathrm{Cl}^{-}\right)$in the local (Area I) and bulk domain (Area II) areas is controlled by properties of the electrical double layer-EDL (see Cevc, 1990); EDL is characterized by the ion profile around the membrane, as well as the electrical field around the membrane, between $\psi_{0}$ and $\psi_{\text {bulk }}$. (cf. Figure 2). Photosynthetic proton pumping into the lumen is accompanied by counter-ion transport from lumen into stroma. The process of electron transport and the use of protons by ATPase can be uncoupled by the addition of various ionophores (nigericin-electroneutral antiporter $\mathrm{H}^{+} / \mathrm{K}^{+}$; valinomycin $-\mathrm{K}^{+}$ionophore; A23187- $\mathrm{Mg}^{2+}$ ) that can disrupt the membrane potential and ion/proton gradients. The efficient activity of the particular ionophore in uncoupling requires the presence of appropriate cationic species at the membrane surface (Barber, 1980b); therefore, their uncoupling ability differs between high \& low screening modes when more $\mathrm{Mg}^{2+}$ and $\mathrm{K}^{+}$are attached to thylakoid membranes (see Figure $\mathbf{5}$ ) 
the membrane $(\Delta \psi)$ are tightly interconnected as they both form an "electrical double layer"-EDL (see Figures 1, 2). Here, we have a typical heterogeneous structure defined by charges and by electrical fields formed close to the negatively charged membranes (Cevc, 1990). In chloroplasts, both monovalent and divalent cations electrostatically interact with negatively charged surface of the thylakoid membrane proteins (see e.g., Barber, 1980a,b, 1982, 1986, 1989), and both the free ions and the fixed charges of membrane proteins form the EDL of the thylakoid membrane (Figure 2). Any change in heterogeneous EDL affects reactions in photosynthesis (Barber, 1980b).

The original chemiosmotic theory did not include any heterogeneity in ions or in proton concentrations (Mitchell, 1961, 1966). It had suggested that ATP synthesis is driven by equilibrated proton gradient between two homogenous cellular compartments in the bulk aqueous phases (see Figure 1); this type of photophosphorylation is considered to be delocalized. Even though the theory was experimentally

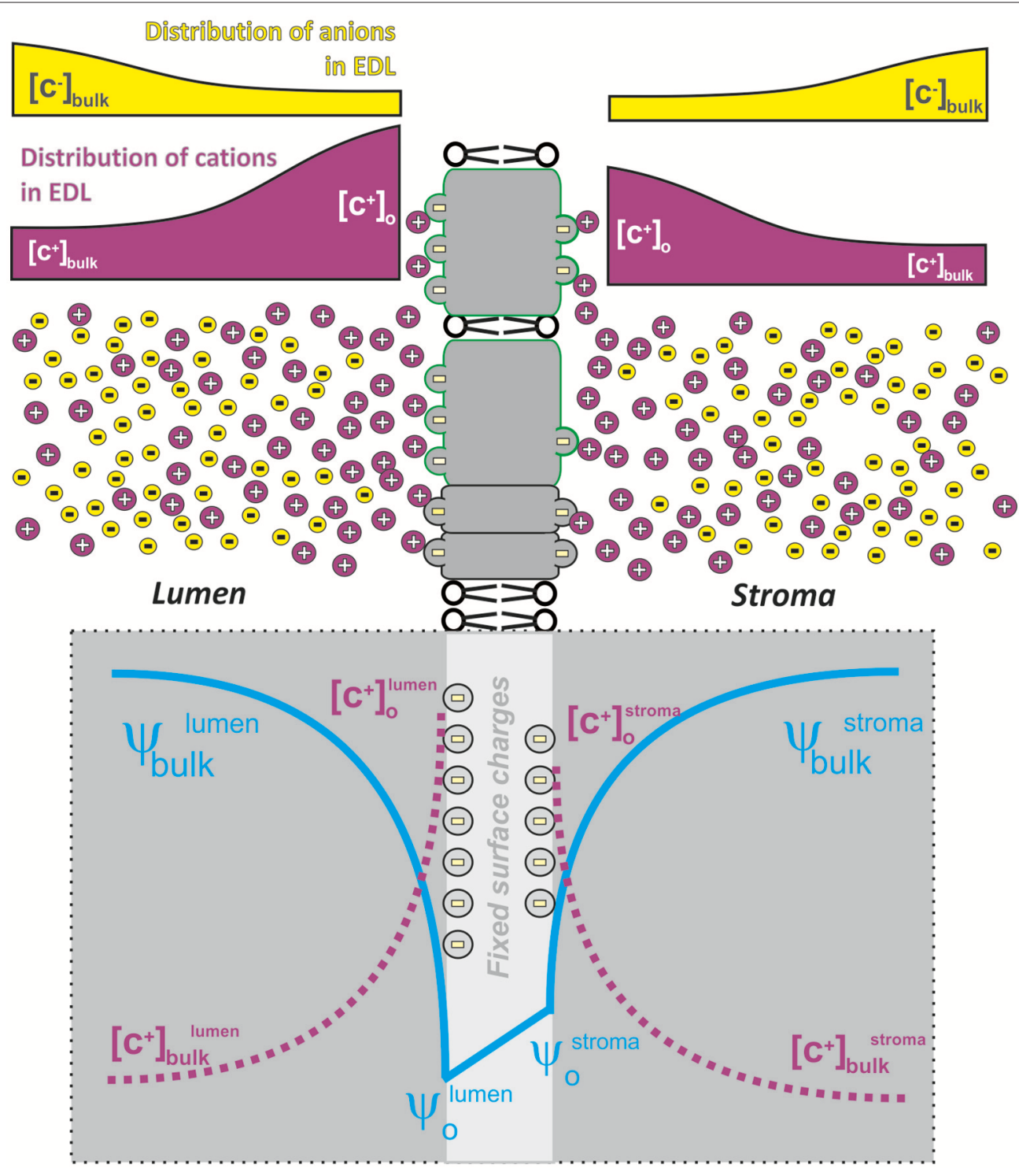

FIGURE 2 | A schematic representation of charge/electrostatic field distribution around thylakoid membranes that forms electric double layer (EDL). Negatively charged amino acid residues form fixed charges on the thylakoid membrane surface that is screened by positive ions (mostly Mg $2+$ ) in the lumen as well as in the stroma. The concentration of screening cations decreases with distance from the membrane surface in contrast to that of the anions that are more abundant farther from the negative charges of the membrane. This charge distribution then forms the electric double bilayer (EDL) where the electrical field (see blue line) on the luminal/stromal surface of thylakoid membrane ( $\psi_{0}$-lumen, $\psi_{0}$-stroma) is higher than the electrical field measured in the bulk ( $\psi_{\text {bulk }}{ }^{\text {lumen; } ; ~} \psi_{\text {bulk }}{ }^{\text {stroma }) ; ~ t h e r e ~ i s ~ a l s o ~ a ~}$ characteristic distribution (see dotted magenta lines) in the concentration of cations at the membrane $\left[\mathrm{C}^{+}\right]_{\mathrm{o}}$ and in the bulk $\left[\mathrm{C}^{+}\right]_{\text {bulk. }}$. EDL then represents asymmetric charge distribution of both the anions (e.g., $\left.\mathrm{Cl}^{-}\right)$and the cations $\left(\mathrm{K}^{+} ; \mathrm{Mg}^{2+}\right)$ caused by fixed charges on the thylakoid membrane; the concentration of the anions/cations progressively increases/decreases with the distance from the charged thylakoid membrane surface (Barber et al., 1977). The difference between $\psi_{\text {bulk }}-\psi_{0}$ is characterized by the extent of electrostatic screening - the higher the electrostatic screening by the ions the lower is the observed difference. 
confirmed (see e.g., Junge et al., 1968) some experimental data indicated that proton transfer can sometimes proceed much faster between localized proton domains, situated close to the negatively charged membrane surfaces (Figure 1) by the so-called "localized photophosphorylation" (Dilley, 2004; Mulkidjanian et al., 2006). Importance of localized and/or delocalized photophosphorylation at particular physiological conditions needs to be reconsidered (Dilley, 2004). Therefore, it is obvious that the pmf partitioning must be studied with consideration of the heterogeneous EDL membrane (Figures 1, 2). Moreover, theoretical model has shown an effect of $\mathrm{H}^{+} / \mathrm{ATP}$ stoichiometry, ionic strength, and buffering capacity on pmf partitioning (Lyu and Lazár, 2017). There are also some other, alternative models of photophosphorylation proposing higher importance of ions; for example there is a mechanochemiosmotic photosphorylation model, where ATP synthase is considered as a " $\mathrm{Ca}^{2+} / \mathrm{H}^{+}-\mathrm{K}^{+}$pump-pore enzyme" (Kasumov et al., 2015). Last but not the least, there is not only heterogeneity in the distribution of protons (localized/delocalized), but also in the cations (monovalent $\mathrm{K}^{+}$and divalent $\mathrm{Mg}^{2+}$ ) that seems to be distributed asymmetrically- $\mathrm{K}^{+}$being mostly in the bulk of the stroma and $\mathrm{Mg}^{2+}$ ions being associated closely with the thylakoid membranes due to their divalent charges (see e.g., Barber, 1980b, 1982; references therein).

In summary, protons and ions are distributed heterogeneously in close vicinity of negatively charged thylakoid membrane surface (see Figures 1, 2). The attraction of ions close to the membrane surface results in screening of the electric field generated by the membrane surface charge. We note that ion screening of membrane charges represents an electrostatic interaction, and it differs from direct neutralization of membrane charges by ions (e.g., $\mathrm{H}^{+}$binding to amino acid residues, see Barber, 1980a). The extent of this screening affects photosynthesis in various ways; effects have been observed on, e.g., variable chlorophyll (Chl) a fluorescence (Murata, 1969a), through changes in chlorophyll-proteins, in thylakoid membrane (TM) stacking (Barber, 1980a), and in excitation energy redistribution during light-induced state transitions (see e.g., Barber, 1982; Staehelin and Arntzen, 1983; Telfer et al., 1983). The direct binding of some ions (e.g., $\mathrm{Zn}^{2+}$ or $\mathrm{Li}^{3+}$ ) or protons at low $\mathrm{pH}$ represents a different effect when membrane stacking is not connected with fluorescence changes (Barber, 1980a). In the following, we describe the role of EDL (i.e., membrane screening), charge neutralization on the membrane (i.e., direct ions interaction with the membrane) on variable $\mathrm{Chl}$ $a$ fluorescence and on the regulation of light-harvesting in state transitions and during non-photochemical quenching.

\section{VARIABLE CHLOROPHYLL $A$ FLUORESCENCE OF PHOTOSYSTEM II}

The light-harvesting efficiency and the photochemistry in the photosystems (especially Photosystem II, PSII) are often inferred from variable $\mathrm{Chl} a$ fluorescence measurements (see e.g., chapters in Papageorgiou and Govindjee, 2004). At room temperature, the ratio of variable to minimal chlorophyll $a$ fluorescence
$\left(\mathrm{F}_{\mathrm{v}} / \mathrm{F}_{\mathrm{m}}=\left(\mathrm{F}_{\mathrm{m}}-\mathrm{F}_{\mathrm{o}}\right) / \mathrm{F}_{\mathrm{m}}\right.$, where $\mathrm{F}_{\mathrm{m}}$ is the maximal fluorescence for totally closed reaction centers of PSII, $F_{O}$ is the minimal fluorescence at very low excitation intensity, and $\mathrm{F}_{\mathrm{v}}$ is the variable fluorescence, see Figure 3) has been extensively used as a measure of the efficiency of PSII photochemistry (Krause and Weis, 1991; Govindjee, 2004) since PSI fluorescence is very low and constant (see Giovagnetti et al., 2015; references therein). The kinetic changes in variable chlorophyll $a$ fluorescence reflect several processes affected by electron transport, protonation, phosphorylation, NPQ in the antenna, and in PSII reaction centers, as well as in excitation energy redistribution between the two photosystems during state transitions.

Time dependent variable $\mathrm{Chl} a$ fluorescence intensity changes (fluorescence induction, or fluorescence transient) is measured when dark-adapted cells are exposed to high light; the first measured point is the " $\mathrm{O}$ " level, the $\mathrm{F}_{\mathrm{o}}$, the initial fluorescence (Figure 3). This is followed by an increase to the " $\mathrm{P}$ " level (in ms range), due mainly to the reduction of $Q_{A}$ to $Q_{A}^{-}$. An effect of other processes including electric field, and conformation of proteins is a matter of discussion for the first second after the sample is exposed to light (see e.g., Schansker et al., 2014 for a review). For instance, the non-photochemical thermal (JIP, see Samson et al., 1999) phase can be attributed to the release of quenching of fluorescence associated with light-driven conformational changes in PSII (Schansker et al., 2011), or of "photoelectrochemical quenching" controlled by trans-thylakoid proton pump, powered by light-driven Q cycle (see Vredenberg et al., 2009, 2012). The fast Chl $a$ fluorescence rise, during the first second of illumination (Figure 3B) is labeled as a $\mathrm{O}-\mathrm{J}-\mathrm{I}-\mathrm{P}$ transient ( $\mathrm{O}$ for the minimum fluorescence, $\mathrm{J}$, and I for inflections, and $\mathrm{P}$ for the peak (Strasser et al., 1995; Lazár, 1999, 2006; Stirbet and Govindjee, 2012; Schansker et al., 2014). However, the slower changes in fluorescence (in tens of seconds, to minutes, see Figure $3 \mathbf{A}$ ) reflect changes in other physiological processes, including state transitions, nonphotochemical quenching, and even photoinhibition.

Chlorophyll $a$ fluorescence transients, during both fast $(\sim$ in seconds) and slow (in minutes) time range, have different characteristics in plants, and in cyanobacteria (Ruban and Johnson, 2009; Papageorgiou and Govindjee, 2011; Kaňa et al., 2012a; Kirilovsky et al., 2014). These transients are affected by changes in several factors including: (a) the efficiency of PSII photochemistry (reflected by the OJIP phase); (b) state transitions (Ruban and Johnson, 2009); (c) the coupling and uncoupling of antenna from PS I and or PS II (Kaňa et al., 2009; Kirilovsky et al., 2014); (d) photoinhibition of PSII in high light (Prášil et al., 1992); (e) lumen acidification during NPQ (e.g., Ruban et al., 2012; Zaks et al., 2013; also see Demmig-Adams et al., 2014); (f) the efficiency of carbon cycle reactions; and (g) divalent and monovalent ion concentrations that affect EDL, as well as the electric properties of thylakoid membranes (Barber and Mills, 1976; Barber, 1980b, 1982).

The effect of ionic composition of the suspension medium on variable Chl a fluorescence of chloroplasts and thylakoid membranes has been intensively studied during the 1970s1980s (Vandermeulen and Govindjee, 1974; Barber and Mills, 1976). Ion dependent NPQ of Chl $a$ fluorescence at room 

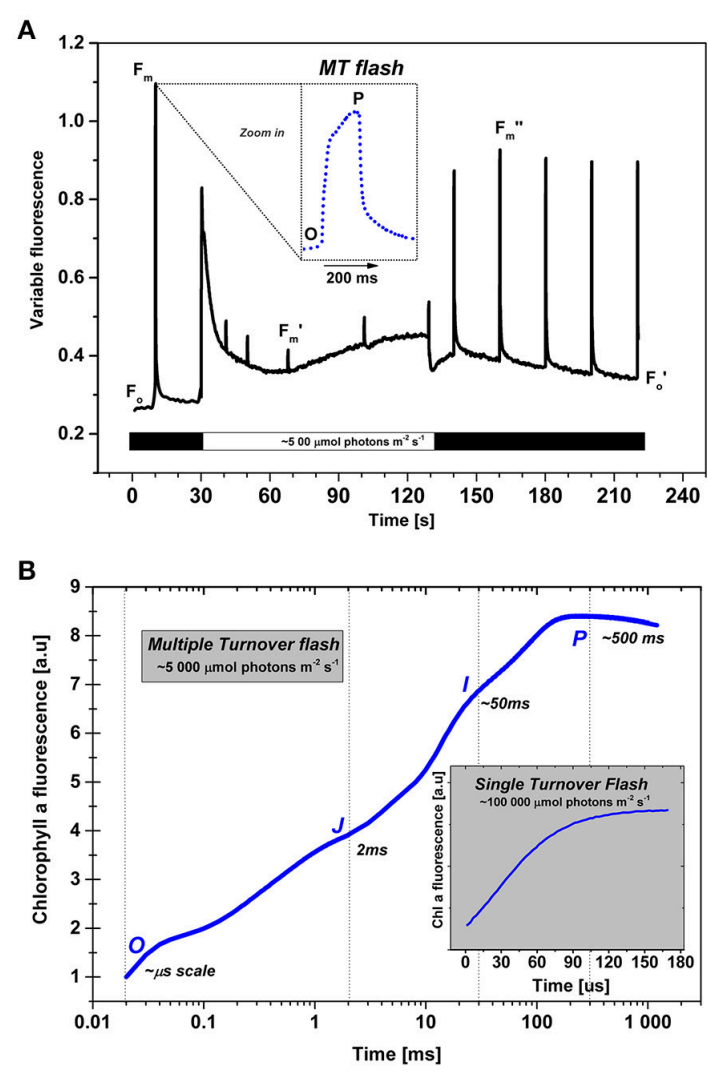

FIGURE 3 | Chlorophyll a fluorescence measurements in photosynthetic organisms. (A) (top): A protocol used for the detection of PSIl photochemistry upon exposure with $\sim 500 \mu \mathrm{mol}$ photons $\mathrm{m}^{-2} \mathrm{~s}^{-1}$ light (Krause and Weis, 1991). The minimal level of Chl a fluorescence of open PSII reaction centers plus that from $\mathrm{PSI}$ is $\mathrm{F}_{\mathrm{O}}$; it is measured in a dark adapted sample at very low ("measuring") light $\left(\sim 5 \mu \mathrm{mol}\right.$ photons $\left.\mathrm{m}^{-2} \mathrm{~s}^{-1}\right)$. The maximal fluorescence in dark-adapted sample is $F_{m}$, but its changed value during actinic light is referred to as $\mathrm{F}_{\mathrm{m}^{\prime}}$, and after the actinic light period light, it is labeled as $\mathrm{F}_{\mathrm{m}^{\prime \prime}}$. In the experiment shown, it was measured with high intensity multiple turnover (MT) flashes $\left(\sim 1500 \mu \mathrm{mol}\right.$ photons $\mathrm{m}^{-2} \mathrm{~s}^{-1}$, flash duration $200 \mathrm{~ms}$ ), given for a short period ( 200 ms). (Note: MT flash induces multiple events of charge separation in PSII.) The fluorescence increase during the MT flash has a characteristic polyphasic rise to a plateau or a peak (see inserts in both panels $A$ and $B$ ). The $F_{m}$ and $F_{m^{\prime}}$ (as well as $F_{m^{\prime \prime}}$ ) values are used for the calculation of PSIl photochemistry as well as for

non-photochemical quenching (NPQ) of the excited state of Chl a, the latter equals $\left(\mathrm{Fm}-\mathrm{Fm}^{\prime}\right) / \mathrm{Fm}$. Black bars (near the abscissa) represent periods without actinic irradiation (i.e., darkness), whereas during the open (clear) bar, actinic light is on. The sample used in the experiment shown here was Rhodomnas salina cells (from Kaňa et al., 2012b). (B) Chl a fluorescence transient measured at high intensity ( $5000 \mu \mathrm{mol}$ photons $\mathrm{m}^{-2} \mathrm{~s}^{-1}$ ) MT flash (from Kaňa et al., 2008). The inset shows Chl a fluorescence transient in a short, $100 \mu$ s long, single turnover (ST) flash, at very high irradiation $(\sim 100000 \mu \mathrm{mol}$ photons $\left.\mathrm{m}^{-2} \mathrm{~s}^{-1}\right)$. Using the MT flash at high light intensity, we observe a polyphasic O-J-I-P fluorescence transient, where the O-J rise is due to primary photochemical reactions, the subsequent J-I-P transient being the thermal phase (cf. Stirbet and Govindjee, 2012). The fluorescence rise in single turnover (ST) flash (see inset in $\mathbf{A}$ ) is the fast O-J-I-P fluorescence change during the single charge separation event induced by the ST flash that closes all the PSII reaction centers in a very short period (in about 30-100 $\mu \mathrm{s}$ ) due to the extremely high intensity of light $\left(\sim 100,000 \mu \mathrm{mol}\right.$ photons $\mathrm{m}^{-2} \mathrm{~s}^{-1}$, duration $100 \mu \mathrm{s})$. We note that explanation of experimental differences between ST and MT fluorescence parameters, obtained with single and multiple turnover flashes, requires detailed knowledge of the studied model organism (see e.g., Kolber et al., 1998; Koblížek et al., 2001). temperature has been examined in green algae (Mohanty et al., 1974), in guard cells of Vicia faba (Ogawa et al., 1982), as well as in cyanobacteria (Papageorgiou and Stamatakis, 2004). The effect of $\mathrm{Mg}^{2+}$ has also been examined by low temperature $(77 \mathrm{~K})$ fluorescence spectra in plants. Further, variable Chl a fluorescence during the J-(I)-P phase (Figure 3B) of fluorescence induction may also be affected, in general, by electric field on the thylakoid membrane, as well as by PSI-dependent photoelectric stimulation and transient release of "photo-electrochemical quenching" affected by trans-thylakoid proton pump, which, in turn, also involves the Q cycle (Vredenberg and Bulychev, 2002; Vredenberg et al., 2009, 2012). Even though the Vredenberg model has not been generally accepted, mainly, due to several controversial assumptions (see e.g., Stirbet and Govindjee, 2012), the effect of electrical field and ions on total variable Chl a fluorescence must be taken into account in light of other experimental data, i.e., the effect of valinomycin, a $\mathrm{K}^{+}$ionophore, on the thermal phase of $\mathrm{Chl} a$ fluorescence induction (Pospísil and Dau, 2002; Antal et al., 2011), and the effect of ions on variable Chl $a$ fluorescence in vivo (Mohanty et al., 1973, 1974; Ogawa et al., 1982; Papageorgiou and Stamatakis, 2004; Krupenina and Bulychev, 2007). The effect of cations and or electrical field on fluorescence could also be related to the EDL in thylakoids, formed by ions and fixed membrane charges (see Figure 2; Cevc, 1990). Different screening (low/high-i.e., due to electrostatic interactions) of the membrane charges by ions interferes with the light harvesting process in many aspects, and it is clearly seen through changes of variable fluorescence during organization (or reorganization) of thylakoid membranes (Barber, 1980a,b, 1982, 1986, 1989).

\section{THE ELECTRICAL DOUBLE LAYER (EDL) AND THE THYLAKOID MEMBRANE}

The electrical double layer (EDL) represents a typical structure formed when (biological) membrane surfaces, with fixed negative charges on them, are in contact with an aqueous medium containing cations (Cevc, 1990); here, then, we have asymmetric charge distribution of ions that progressively increases toward electrically charged surfaces, i.e., thylakoids (Figure 2). The definition of EDL is based on changes of electrical field $\left(\psi_{0}\right.$ a parameter measurable by electrochromic shift (Cruz et al., 2001) and ion concentration $\left(\left[\mathrm{C}^{+}\right]\right.$with increasing distance from the membrane; Figure 2). In fact, ions located close to the membrane surface result in screening of the electric field of the membrane surface charge (i.e., damping of electrostatic field of fixed charges caused by the presence of interacting ions). The term screening in this case describes the ability of ions in the aqueous phase to increase the negative surface potential closer to zero (see $\psi_{\mathrm{o}}$ in Figure 2; for details and equations, see e.g., Barber, 1980b) and it is different than direct interaction of ions with the membranes (i.e., charge neutralization, see Barber, 1980a).

The thylakoid membrane is negatively charged at physiological pH (see reviews Barber, 1980b, 1982; references therein). The average area per single electronic charge on the thylakoid membrane has been estimated to be about $10 \mathrm{~nm}^{2}$ 
(Barber, 1980b). Based on isoelectric measurements on isolated thylakoids (Akerlund et al., 1979), the total fixed negative charges on thylakoid membranes have been estimated to be higher on their luminal, than on their stromal, surface. There are also some experiments indicating an increase in the fixed negative charge during irradiation (see discussion in Barber, 1982) and reference therein). These charges can be attributed to the carboxyl groups of glutamic and aspartic acids in the pigment protein complexes that are negatively charged at the physiological pH (cf. Behrens et al., 2013). An involvement of negatively charged lipids (sulfoquinovosyldiacylglycerol and phosphatidylglycerol) in the total charge, on the thylakoid membrane, is still unclear since these lipids represent only about $20 \%$ of all the lipids and they are mostly the boundary lipids for the membrane proteins or act as their cofactors (see e.g., Mizusawa and Wada, 2012). However, the effect of anionic lipids and negatively charged domains of chlorophyll-containing proteins on antenna aggregation/dis-aggregation is indeed a reality (Schaller et al., 2011, 2014). Therefore, the involvement of negatively charged lipids in the total thylakoid membrane charges and on the organization of membrane proteins needs to be further explored.

The EDL in photosynthesis was initially examined for changes in variable Chl $a$ fluorescence intensity at different ion concentrations (Barber and Mills, 1976; Figure 4). This effect is independent of PSII activity since it was measured with PSII inhibited by DCMU (Gross and Hess, 1973). In the simplest model, monovalent $(\mathrm{K}+, \mathrm{Na}+)$ and divalent $\left(\mathrm{Mg}^{2+}\right.$ $\mathrm{Ca}^{2+}$ ) ions have antagonistic effects on chlorophyll a fluorescence (Gross and Hess, 1973; Wong and Govindjee, 1979). In the low salt medium, Chl $a$ fluorescence is inhibited by monovalent ions $\left(\sim 5 \mathrm{mM}\right.$ of $\left.\mathrm{K}^{+}\right)$; however, this inhibition is reversed by the addition of divalent ions (e.g., $\sim 5 \mathrm{mM}$ of $\mathrm{Mg}^{2}$ see e.g., Figure 4B). The decrease in Chl fluorescence intensity by monovalent cations has been rationalized by the presence of divalent cations on the membrane surface, before the addition of monovalent ions (Nakatani et al., 1978); the addition of monovalent ions causes their exchange with divalent ions, and $\mathrm{Chl} a$ fluorescence decreases because monovalent ions have lower capacity of electrostatic screening (Barber, 1989). This effect has been found to be even more complex since $\sim 5 \mathrm{mM} \mathrm{K}^{+}$can reduce Chl $a$ fluorescence in the presence of low $\mathrm{Mg}^{2+}$ (about $0.1 \mathrm{mM}$, see Mills et al., 1976), but the high concentration (e.g., $\sim 50 \mathrm{mM}$ ) of monovalent $\mathrm{K}^{+}$has been shown to enhance variable Chl fluorescence just as low divalent $\mathrm{Mg}^{2+}$ does (Barber et al., 1977; Mills and Barber, 1978). Therefore, the conclusion is that the maximal variable fluorescence can be observed only when positive charge density on the thylakoid membrane surface is sufficiently high and above a critical value (Barber and Mills, 1976).

This dependence of fluorescence on ion concentrations is based only on the valence of interacting ions: a similar effect is observed for $\mathrm{K}^{+}$and $\mathrm{Na}^{+}$, which is different for divalent $\mathrm{Mg}^{2+}$ and $\mathrm{Ca}^{2+}$ (Nakatani et al., 1978); further, there is almost no specificity in ion-protein and in ion-lipid interactions for particular ions (Mills and Barber, 1978). This phenomenon can be thus associated with a delicate interplay of mixed "electrolytes"

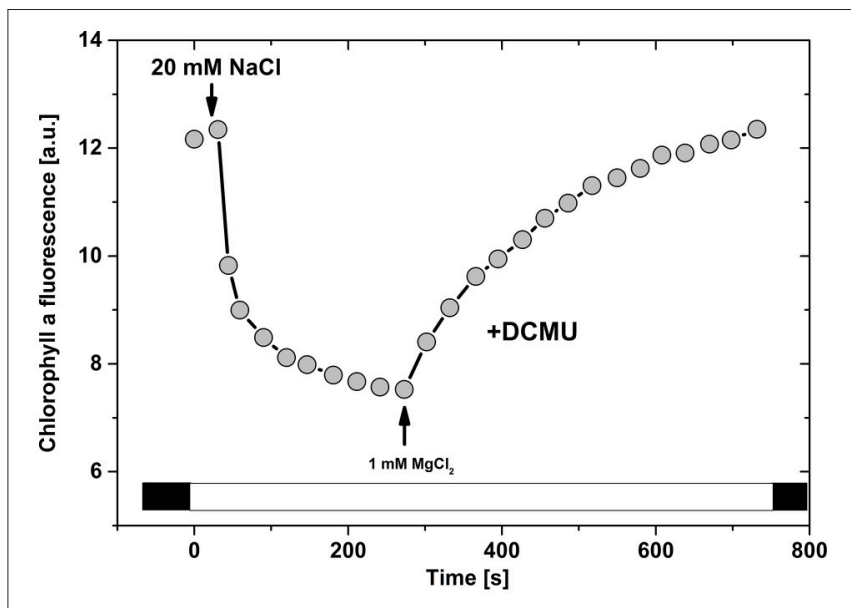

FIGURE 4 | lon induced changes in variable chlorophyll a fluorescence in isolated thylakoids (data adapted from Vandermeulen and

Govindjee, 1974). Time course of cation induced changes in chlorophyll a fluorescence in oat chloroplast suspension containing $5 \mu \mathrm{g}$ chlorophyll $\mathrm{ml}^{-1}$, and $5 \mu \mathrm{M}$ DCMU in low salt buffer. Subsequently, $20 \mathrm{mM} \mathrm{NaCl}$ and $1 \mathrm{mM}$ $\mathrm{MgCl}_{2}$ were added (see arrows).

(e.g., in lumen, or stroma) containing a mix of ions (e.g., $\mathrm{K}^{+}, \mathrm{Mg}^{2+}, \mathrm{Cl}^{-}$, and $\mathrm{Ca}^{2+}$ ) with fixed negative charges of proteins (or lipids) on the thylakoid membranes. These ions can then electrostatically interact with negative charges on thylakoid membranes, thus influencing photosynthesis (Barber et al., 1977). The above-described phenomenon has been theoretically explained by James Barber, and his coworkers, using a modified Gouy-Chapman theory, including non-linear Poisson-Boltzmann ion distribution (Barber et al., 1977). This theoretical approach provided an electrochemical model for EDL on thylakoid membranes at different ion concentrations, and simulated further research in this area (Barber et al., 1977; Rubin and Barber, 1980; Barber, 1989). We can now write several conclusions and caveats: (a) Much lower concentration of divalent cations is required in the bulk solution compared with that of the monovalent cations to provide the same extent of electrostatic screening, as reflected in the surface potential $\left(\psi_{\mathrm{o}}\right)$; (b) The way in which positive charges distribute within the diffuse layer is different for divalent and monovalent cations; (c) The concentration of anions in the diffuse layer is very low. Thus, the observed different effects of particular ions $\left(\mathrm{K}^{+}, \mathrm{Mg}^{2+}, \mathrm{Cl}^{-}\right.$, and $\left.\mathrm{Ca}^{2+}\right)$ on variable Chl $a$ fluorescence can be explained by a pure electrochemical effect, due to their different electrostatic screening of charges of membrane proteins (Rubin and Barber, 1980). We note that the effect, discussed here, does not include direct cation binding on membranes (Barber, 1980a). The direct and unspecific cation binding to negatively charged residues could not be totally ruled out (Mills and Barber, 1978; Barber, 1980a). However, in the case of the direct ion binding to membranes (e.g., for $\mathrm{La}^{3+}, \mathrm{Zn}^{2+}$ or for protons at $\mathrm{pH} 4.3$ ) no fluorescence changes are observed (Figure 4), but only membrane stacking (Berg et al., 1974; Barber and Searle, 1978; Mills and Barber, 1978; Gerola et al., 1979; Barber et al., 1980; Chow and Barber, 1980). 
Therefore, Mills and Barber (1978) and Barber (1980a) concluded that electrostatic forces (i.e., effect of EDL) are responsible for reversible fluorescence changes connected with membrane re-organization.

Different concentrations of monovalent and divalent ions (and their different mixtures) affect EDL properties and produce not only changes in Chl a fluorescence (Figure 4), but they also affect many other photosynthetic processes (see Figure 5 and reviews by: Barber, 1982, 1986, 1989 and Stys, 1995). In the simplest model, we define two extreme states that are characterized by high or poor electrostatic screening (Figure 5). These two extreme states are defined not only by their particular ion concentration, but by their combined effect on $\psi_{0}$ (see e.g., Rubin and Barber, 1980; Barber, 1989). In view of this, the thylakoid membrane seems to be in the same state with "high electrostatic screening" under the following conditions (Figure 5): (i) Divalent cations in the diffuse layer, with a low concentration of monovalent cation in the bulk medium; (ii) Very high concentration of monovalent cations (e.g., $>50$ $\mathrm{mM}$ of $\mathrm{K}^{+}$) in the bulk medium (Barber, 1986). Further high electrostatic screening is found (see Figure 5) under the following conditions: (1) In stacked thylakoid membranes at high $\mathrm{Mg}^{2+}$ (Izawa and Good, 1966) since membrane surface charges regulate membrane-membrane interaction; (2) When there is an increase in Chl $a$ fluorescence yield (Gross and Hess, 1973; Vandermeulen and Govindjee, 1974); (3) When there is a decrease in the "spillover" of excitation energy from Photosystem II (PS II) to Photosystem I (PS I) (Murata, 1969a) separation of PSI and PSII into domains; (4) When there is a transition to high-fluorescence State I (more antenna coupled to PSII); (5) When there is high protein aggregation of antennas and photosystems (we note that protein aggregation, based on current model of NPQ, leads to a quenched state of antennas with low fluorescence yield-this discrepancy needs to be solved by future experiments); (6) In isolated thylakoids, A23187, a $\mathrm{Mg}^{2+} / \mathrm{Ca}^{2+}$ ionophore, is a better uncoupler under high, than low, electrostatic screening mode; the uncoupler activity of all the ionophores (including nigericin $-\mathrm{H}^{+} / \mathrm{K}^{+}$antiporter, valinomycin $-\mathrm{K}^{+}$carrier, gramicidin-cation ionophore, and $\mathrm{A} 23187-\mathrm{Mg}^{2+}$ ionophore) is dependent on adequate supply of appropriate cations at the membrane surface (Barber, 1980b); (7) At high-electrostatic screening mode, there is minimal quenching of fluorescence by "spillover" of excitation energy from PSII to PSI; (8) There is positive coupling of electron transport with phosphorylation (Walz et al., 1971); (9) Higher PSII efficiency at high screening mode is due to a positive effect on water oxidation and reduction of plastoquinone (Dau and Sauer, 1991; Karge et al., 2014; Khan et al., 2015). In conclusion, the switch between the low and the high electrostatic screening is caused by changes in ions and their concentration. This process affects light-harvesting efficiency in photosynthesis, especially during state transitions, or during excitation energy spillover, as monitored by $\mathrm{Chl} a$ fluorescence. In addition, there is also an effect on the NPQ of the excited state of Chl a (Mills et al., 1976). In view of the above observations, we describe below effects of ions on some of these processes.

\section{REDISTRIBUTION OF EXCITATION ENERGY BETWEEN THE PHOTOSYSTEMS, MEMBRANE STACKING AND THE ROLE OF IONS IN STATE TRANSITIONS}

The redistribution of absorbed light between the two photosystems is controlled by state transitions, a process described independently by Bonaventura and Myers (1969) in green algae and by Murata (1969b) in red algae, and discussed soon thereafter by Duysens (1972). This phenomenon was also described earlier, without being named as such, by Papageorgiou and Govindjee (1968a,b), as recognized by Krause and Jahns (2004). This process defined as state transitions has been studied in details in cyanobacteria, green algae, and in higher plants (Ruban and Johnson, 2009; Papageorgiou and Govindjee, 2011; Kirilovsky et al., 2014; Nagy et al., 2014; Kodru et al., 2015). In contrast, fluorescence changes usually attributed to state transitions (see e.g., Allen and Mullineaux, 2004) seem to be absent in algae from the red evolutionary clade (excluding the cryptophytes Cheregi et al., 2015) and the red algae (Kaňa et al., 2014). The basic function of state transitions is redistribution of the absorbed light between the two photosystems (PSI and PSII) which optimizes the overall electron transport since the two systems operate in series (Govindjee and Björn, 2012).

In vivo, the two light-induced states have been defined as: (1) State I-characterized by an increased effective light absorption cross-section of PSII (i.e., a bigger PSII antenna); it is called State 1 because it is induced by light preferentially absorbed by PSI; (2) State II-characterized by an increased effective cross-section of PSI (bigger PSI antenna); it is called State II because it is induced by light preferentially absorbed by PSII antenna (Duysens, 1972; Goldschmidt-Clermont and Bassi, 2015). At room temperature, Chl $a$ fluorescence is high in State I, but in State II, it is low since the quantum yield of PS II fluorescence is much higher than that of PSI due, in part, to the higher rate of photochemistry in PSI than in PSII and persistent quenching of PSI fluorescence by P700. The single unmistakable way to differentiate between State I and State II in green plants, green algae and in cyanobacteria is to compare fluorescence spectra at $77 \mathrm{~K}$. In State I in plants, far-red PS I emission at $735 \mathrm{~nm}$ (F735) is lower compared to that from PSII at $685 \mathrm{~nm}$ (F685), whereas in State II, it is the opposite (Allen and Mullineaux, 2004). We note that in organisms that lack a well-separated far-red emission of PSI [e.g., in red-clade alga Chromera velia (Belgio et al., 2017) and in the dinoflagellate Gonyaulax polyedra (Govindjee et al., 1979)], this method cannot be used.

In addition to state transitions described above for intact cells, ions regulate excitation transfer between photosystems (see e.g., Murata, 1969a; Wong et al., 1979). In fact, fluorescence changes typical for State I and State II can also be induced in isolated chloroplasts/thylakoids that are exposed to different ionic composition (see Figure 4): (1) When exposed to high $\left[\mathrm{Mg}^{2+}\right]$, thylakoids in higher fluorescence State I not only have higher PSII antenna size, but their membranes are in high electrostatic screening mode (Murata, 1969a), and are highly stacked; (2) Low fluorescent State II occurs if the concentration 


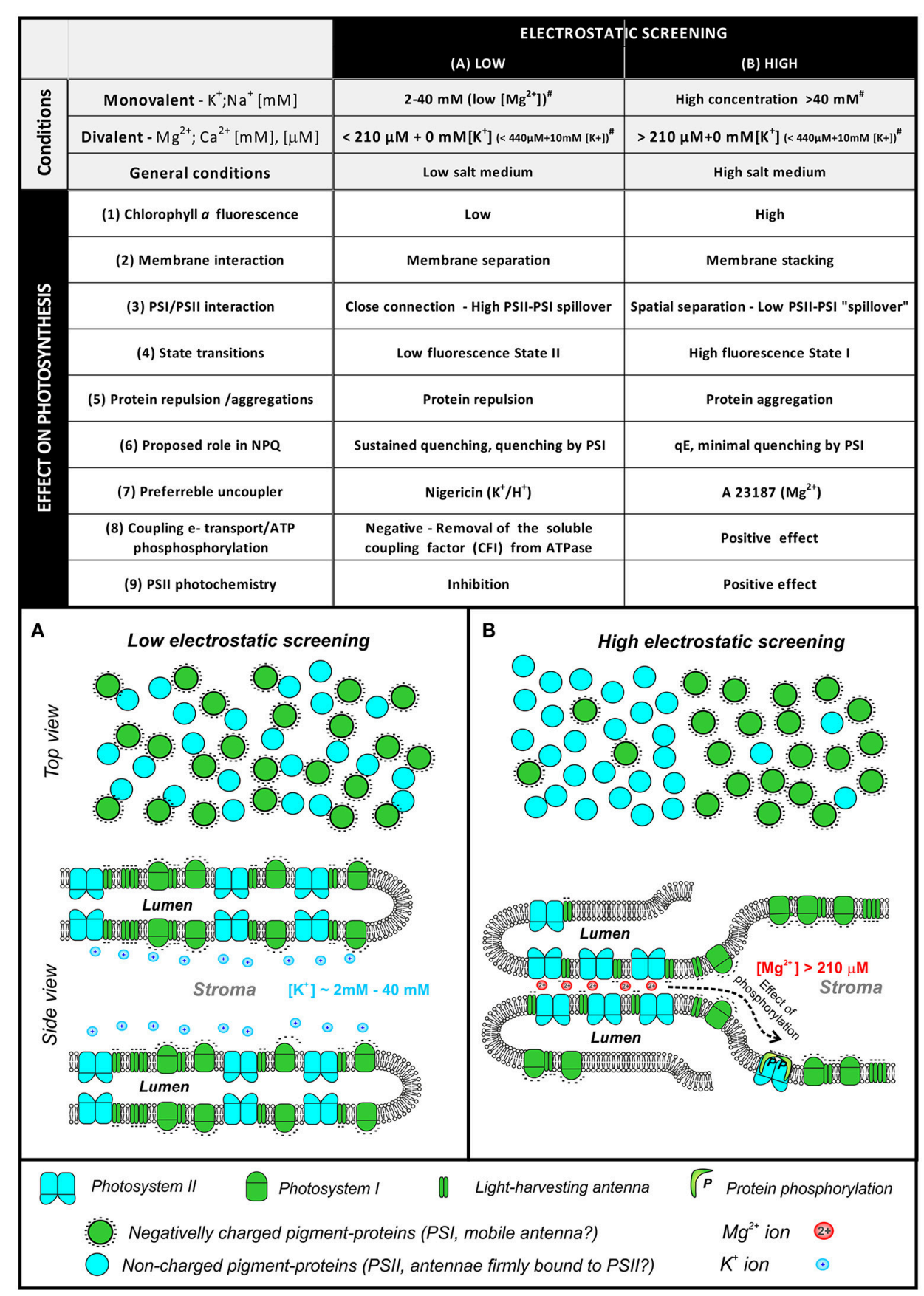

FIGURE 5 | A simplified scheme of changes in protein organization in different states of electrostatic screening (adapted from Barber, 1980b). The table summarizes basic conditions for low or high screening - high screening is induced by high divalent cation content [e.g., $>220 \mu \mathrm{M} \mathrm{Mg}{ }^{2+}$ with no $\left(\mathrm{K}^{+}\right)$, $>440 \mu \mathrm{M}$ $\mathrm{Mg}^{2+}$ with $10 \mathrm{mM}\left(\mathrm{K}^{+}\right)$, see (Mills and Barber, 1978) for details]. The switch between low/high screening mode is a complex interplay between monovalent/divalent cation concentrations as it is described by EDL model of thylakoid membrane (Barber et al., 1977). The low/high screening state is then reflected in various physiological processes including intensity of Chl a fluorescence (low intensity /high intensity), thylakoid membrane stacking or separation, lower/high excitation spillover between photosystems, State II/State I, protein repulsion/aggregation, proposed role in non-photochemical quenching, preferable uncouplers (Mg ${ }^{2+}$ ionophore A23187 vs. $\mathrm{K}^{+} / \mathrm{H}^{+}$antiporter nigericin), effect on electron-proton coupling in photophosphorylation, effect on PSII photochemistry. The screening is caused by ion attachment to membranes that results in screening of the electric-field of the membrane charge (i.e., damping of electrostatic field of fixed charges caused by the presence of interacting ions). (A). Simplified scheme of membrane protein organization in the state of low electrostatic screening. Green cycles represent negatively charged proteins (PSI complex, light harvesting antennas), cyan particles represent less charged PSII. Monovalent cation $\mathrm{K}^{+}$is shown as a dominant ion attached to the negatively charged membrane surface. (B) A simplified scheme of membrane protein organization in the state of high electrostatic screening, divalent cation, $\mathrm{Mg}^{2+}$, is proposed to be the main ion attached to the negatively charged membrane surface. Role of protein phosphorylation on protein redistribution is indicated (\# values were taken from Mills and Barber, 1978). 
$\mathrm{Mg}^{2+}$ cation is lowered to very low values (below $100 \mu \mathrm{M}$, without any other cation like $\mathrm{K}^{+}$, see Mills and Barber, 1978) or in the presence of monovalent cations (e.g., $\sim 5 \mathrm{mM} \mathrm{K}^{+}$) in ion-free medium; in this case, a decrease in PSII fluorescence is considered to be due to State I to State II transition (see Figure 4). We note that milimolar $\left[\mathrm{K}^{+}\right]$and $\left[\mathrm{Mg}^{2+}\right]$, given alone, have opposite effects on fluorescence $\left(\mathrm{K}^{+}\right.$ions decrease, and $\mathrm{Mg}^{2+}$ ions increases fluorescence). However, if they are given together, the effect is more complex (for details, see Mills and Barber, 1978). The fluorescence decrease can be also induced by anions; higher effects are observed with increasing valence (Jajoo et al., 1998, 2001). Therefore, it is clear that anions (Jajoo et al., 1998; Jajoo and Bharti, 1999) and monovalent cations can reverse the effect of $\mathrm{Mg}^{2+}$ that switches thylakoid membranes into a high electrostatic screening mode (see Figure 5). These negative charges act on the outer side of the thylakoid membrane due to the electrostatic interaction with the negative charges of proteins, and this affects the extent of stacking of thylakoid membranes (Barber, 1982).

As a matter of fact, state transitions are triggered by redox shifts of the PQ-pool [the PQ-pool is more reduced in State II (Mullineaux and Allen, 1986)]; in higher plants and in green algae, it is accompanied by phosphorylation of a mobile lightharvesting complex (in State II) (Horton and Black, 1980; Allen et al., 1981; Tikkanen and Aro, 2012). This occurs on the outer surface of thylakoid membranes (for further information, see Vener et al., 2001; Vener, 2007), and contributes to the total negative charge of the outer thylakoid membrane surface. There is a specific STN7 kinase that phosphorylates light harvesting antenna of PSII-LHCII, which is then redistributed to PSI (Bellafiore et al., 2005) during state I to state II transition. On the other hand, another kinase, Stn8, phosphorylates PSII subunits and is involved in PSII repair during photoinhibition (Tikkanen et al., 2008). The current model of state transitions in higher plants involves phosphorylation which leads to addition of negative charges on the mobile LHCIIb phosphate groups provide those charges; this is in agreement with the electrostatic screening model of state transitions that includes a role of negative charges on the pigment proteins (Barber, 1980b, 1982; Staehelin and Arntzen, 1983; Stys, 1995). Indeed, the higher mobility of phosphorylated (mobile) LHCII has been confirmed (see Consoli et al., 2005); see reviews by Mullineaux (2008), Kaňa (2013), Kirchhoff (2014). The connection between electrostatic screening, protein phosphorylation, protein redistribution and membrane organization (stacking/de-stacking) is still not clear; in all likelihood, phosphorylation of PSII in plants exposed to high light enhances the stacking dynamics of the photosynthetic membranes (Barber, 1982; Fristedt et al., 2010).

The molecular mechanism of excitation energy redistribution during state transitions is either due to antenna (LHC II) redistribution between the two photosystems, or a change in PSI/PSII interaction. The latter causes differences in "excitation energy spill over" from one system to another (from the "slower" PSII to the "faster" PSI, see e.g., Mirkovic et al. (2016) where PSI acts as an efficient fluorescence quencher (Barber, 1982; Slavov et al., 2013). In some cases, the antenna uncoupled from one photosystem (e.g., from PSII) is not necessarily coupled to the other photosystem (e.g., PSI) and remain(s) uncoupled in the membrane (Kaňa et al., 2009; Kirilovsky et al., 2014; Unlu et al., 2014; Cheregi et al., 2015). The role of these uncoupled antennas needs to be taken into account in any future model of state transitions (Goldschmidt-Clermont and Bassi, 2015). Based on the correlation between state transitions, membrane stacking and ion composition, and interconnection between state transition mechanism and changes in electrostatic screening (Barber, 1980a), we may very well consider combining the phenomenon of electrostatic screening with the current model of state transitions in higher plants that requires getting a negative charge through phosphorylation (Tikkanen and Aro, 2012). We note that phosphorylation can have a dramatic effect on the membrane surface charge as there are multiple phosphorylation sites on PS II, and each phosphorylation provides two negative charges at a stromal $\mathrm{pH}$ of 8.0. Further experiments and analysis are needed to reach this goal.

The molecular mechanism of state transitions representing antenna redistribution and/or change in excitation energy spillover between PSII/PSI is caused by a variation in the balance between electrostatic repulsion (coulombic repulsive forces between negative charges of proteins affected by electrostatic screening) and protein attraction caused by van der Waals forces that are independent of charges on the proteins (see e.g. Barber, 1980b; Stys, 1995). The higher/lower electrostatic screening of negatively charged proteins by ions affects the balance between protein repulsion (low electrostatic screening, Figure 4) and attraction (high electrostatic screening). This concept is based on Derjaguin-Landau-Vervey-Overbeek (DLVO) theory for the aggregation of colloids-more divalent cations lead to membrane stacking due to reduction in electrical repulsion (Barber, 1982; Stys, 1995). This process occurs in vitro when changes in $\left[\mathrm{Mg}^{2+}\right]$ affect PSII LHCII interactions (see e.g., Kiss et al., 2008). Moreover, membrane stacking can be induced also by lowering of stromal $\mathrm{pH}$ to about 5.4 inducing electrostatic neutralization (i.e., by increasing $\left[\mathrm{H}^{+}\right]$), which is closer to the isoelectric point of the thylakoid membrane (Gerola et al., 1979; Jennings et al., 1979). The stimulating effect of low $\mathrm{pH}$ on stacking has also been shown in the light-induced spontaneous tendency of thylakoid membranes to stack (Janik et al., 2013). Proteins can lose charges when the $\mathrm{pH}$ of the medium is close to the pKs of their negatively charged amino acids (Nakatani and Barber, 1980; Behrens et al., 2013); close to their pKs, proteins become electroneutral. However, in this case membrane stacking is usually caused by charge neutralization, not by charge shielding through EDL. Moreover, this effect is not connected with protein redistribution and with fluorescence changes (Barber, 1980a).

However, when thylakoid membranes stack, Chl a fluorescence increases, and State I induced by high $\mathrm{Mg}^{2+}$ (high electrostatic screening state, see Figure 5) usually appears simultaneously (Barber, 1980a; Barber et al., 1980). In this model, which is based on EDL, ion-dependent effects on antenna proteins are single regulatory events [e.g., re-arrangement of different super complexes at different $\left[\mathrm{Mg}^{2+}\right]$ inducing stacking of thylakoid membranes leading to changes in Chl $a$ fluorescence (Rumak et al., 2010)]. However, there are some special cases when they occur independently of each other, usually when direct 
charge neutralization (direct ion/proton binding) occurs (Mills and Barber, 1978; Barber, 1980a). An example is $\mathrm{Mg}^{2+}$ induced antenna coupling with PSII, without membrane stacking (Kiss et al., 2008); whether this is because of electronic screening, or neutralization, needs to be ascertained (Mills and Barber, 1978; Barber, 1980a; Scoufflaire et al., 1982). However, we speculate that these ion-induced effects (membrane stacking/fluorescence changes) are controlled by two different mechanisms that usually, but not always, co-occur.

In fact, the two independent processes induced by $\mathrm{Mg}^{2+}$ addition have also been shown to exist through fluorescence measurements (Jennings et al., 1982). In one case, an ion effect has been shown to work only on the stromal side (e.g., by the application of impermeable poly L-lysine): there was restacking without fluorescence increase (Berg et al., 1974). Moreover, it has been clearly shown that ion-induced thylakoid stacking/unstacking in the grana region can appear without any change in variable Chl $a$ fluorescence, and without any change in the connectivity between different units of antenna (Kirchhoff et al., 2004), again depending on whether electrostatic screening or neutralization is present (Mills and Barber, 1978; Barber, 1980a; Scoufflaire et al., 1982). On the contrary, these phenomena are found to be connected in thylakoids (granal and stromal membranes) indicating the importance of stroma for thylakoid membrane reorganization (Kirchhoff et al., 2004). This indicates a role of a stromal factor, or a requirement of less-protein-crowded stromal thylakoids for grana reorganization. Based on the hypothesis proposed by Barber (1980a), the membrane stacking connected with fluorescence changes represents a switch between high/low electrostatic screening (i.e., it is an effect of electrostatic interaction-EDL); the disconnection between fluorescence and membrane stacking is caused by the presence of membrane charge neutralization, which means direct interaction of ions (or protons) with membrane charges. There are also some other experimental data indicating that proton/ion regulation of lightharvesting requires at least two independent regulatory events (Wollman and Diner, 1980; Jennings et al., 1982; Kirchhoff et al., 2003, 2004; Stoitchkova et al., 2006; Kiss et al., 2008); plausible candidates for these effects could be screening or binding of ions (Barber, 1980a). However, to explore conditions, when these processes (i.e., membrane stacking and state transitions) are independent, additional experiments affecting the ratio of ion screening/ion binding are needed to confirm the proposed concepts.

The mechanism of state transition(s) requires a certain reorganization of thylakoid membrane proteins. The positive effect of protein phosphorylation on structural flexibility of the thylakoid membrane architecture has been confirmed (Varkonyi et al., 2009). Thylakoid membrane proteins are also differently organized (random or into domains) for different electrostatic screening (low or high; see Figure 4; Barber, 1982). The movement of these differently charged proteins is induced by lateral charge displacement on the outer side of the thylakoid membranes (see e.g., Barber, 1986); this can be induced either by protein phosphorylation higher mobility of phosphorylated (mobile) LHCII (Consoli et al., 2005) or by some unspecific effects of ions causing columbic repulsion between PSII and
PSI. We note that only with screening (i.e., electrostatic effect of ions without interaction), we have lateral diffusion of PSI (in stroma lamellae) and of PSII (in grana), as well as changes in spillover from PSII to PSI. With neutralization of surface charges by ion binding (e.g., protonation at low $\mathrm{pH}$, Barber et al., 1980), the membranes simply collapse on each other to give a grana-like appearance with no lateral separation of PSI and PSII. Therefore, increase in the electrostatic screening leads to the formation of heterogeneous domains of low-charge/high-charge, resulting in fluorescence changes (Barber et al., 1980).

\section{REGULATORY ROLE OF PROTONS AND IONS IN TRIGGERING NON-PHOTOCHEMICAL QUENCHING OF THE CHLOROPHYLL EXCITED STATE}

Non-photochemical quenching (NPQ) of the excited state of chlorophyll $a$ is a process that protects PSII against excess light (Ruban et al., 2012; Zaks et al., 2013; Croce and Van Amerongen, 2014); for further details see Demmig-Adams et al. (2014) by stimulating the dissipation of excessive irradiation into heat (Kaňa and Vass, 2008). NPQ significantly reduces the quantum yield of variable fluorescence (by even $60 \%$, see Ostroumov et al., 2014) and affects the efficiency of energy transfer from the antenna to the reaction centers (see review on the energytransfer dynamics in photosynthesis Mirkovic et al., 2016). In higher plants, NPQ occurs mainly in the light-harvesting antenna (Gilmore et al., 1995; Horton et al., 1996; Belgio et al., 2012). However, in cold tolerant plants or in certain extremophiles (algae or cyanobacteria), closed PSIIs can also act as quenchers (see e.g., Ivanov et al., 2008; Krupnik et al., 2013). Kinetically, NPQ is divided into at least three major components: (1) the "energy dependent" quenching $(\mathrm{qE})$, which is triggered by a faster $(<1 \mathrm{~min})$ light-driven proton translocation across the thylakoid membrane (Barber, 1976; Krause et al., 1983); (2) a slower, less dominant, quenching component that has been attributed to state transitions (qT-Allen et al., 1981); and (3) slowest components, such as zeaxanthin-dependent quenching, qZ (Nilkens et al., 2010; Ocampo-Alvarez et al., 2013), and a photoinhibitory quenching, qI (Krause, 1988), more generally, simply a "sustained quenching" (Ruban and Horton, 1995).

The triggering role of protons in $\mathrm{qE}$ activation was proposed for the first time by Wraight and Crofts (1970) for cyclic electron flow in samples where PSII activity was inhibited by DCMU, and diaminodurene (DAD), a mediator of PSIdependent electron transport stimulating $\Delta \mathrm{pH}$, was added (see discussion in Papageorgiou and Govindjee, 2011). The triggering of $\mathrm{qE}$ by luminal protons in vivo was established directly by $\mathrm{pH}$ titration in isolated chloroplasts (Briantais et al., 1979). Finally, a direct protonation of pigment-proteins has been observed in vitro (Ruban et al., 1994; Walters et al., 1996; Kaňa et al., 2012b; Xiao et al., 2012; Belgio et al., 2013). The qE sensitivity to luminal protons is controlled by various allosteric regulators (see the details of the concept in Ruban et al., 2012) including xanthophylls (e.g., zeaxanthin, and violaxanthin Niyogi et al., 
1998; Kaňa et al., 2016) and the PsbS protein (see e.g., Li et al., 2000; Johnson and Ruban, 2010).

The co-regulation of low $\mathrm{pH}$-induced $\mathrm{qE}$ with ions, and with electrostatic screening of thylakoids, is not clear. Noctor et al. (1993) have shown that a relatively high concentration of $\mathrm{Mg}^{2+}$ (about $10 \mathrm{mM}$ ) is necessary to obtain maximal $\mathrm{qE}$ in isolated thylakoids. This $\mathrm{Mg}^{2+}$-dependent mechanism for NPQ (probably related to quenching by PSI, see below) can be also induced by changes in $\mathrm{Mg}^{2+}$ concentration in the dark (Briantais et al., 1979; Krause et al., 1983). This could indicate that the maximal extent of flexible $\mathrm{qE}$ requires high electrostatic screening of thylakoid membrane charges, which means a higher content of $\mathrm{Mg}^{2+}$ on the thylakoid surface (see Figure 5). However, some specific effects of ions on antenna aggregation, and, thus, fluorescence quenching, cannot be totally excluded. Mills et al. (1976) have suggested existence of a cation-sensitive site influencing fluorescence on the stromal surface of thylakoids, based on a similar effect of impermeable choline and $\mathrm{K}^{+}$on fluorescence decrease. A possible ionic effect of $\mathrm{K}^{+}$has also been shown for the "slow" component of NPQ based on experiments with added valinomycin, a specific $\mathrm{K}^{+}$ionophore (Sokolove and Marsho, 1979). However, this data, seemingly, contradicts earlier data showing that $\mathrm{qE}$ is sensitive only to $\mathrm{K}^{+} / \mathrm{H}^{+}$antiporternigericin, but not inhibited by valinomycin (Wraight and Crofts, 1970). Therefore, further experiments that would more carefully consider screening mode (high/low-see Figure 5) are needed to resolve the above-mentioned discrepancy.

Ion concentration can also affect Chl a fluorescence quenching in vivo (Mohanty et al., 1974; Ogawa et al., 1982); however, the mechanism of its effect is not yet clear. Further, we could propose a different mechanism for qE-triggering at low electrostatic screening of thylakoid membrane charges (see Figure 5) when spillover of excitation energy from PSII to PSI may be increasing - in this case, PSI may be acting as a fluorescence quencher. A similar mechanism for NPQ has been proposed for desiccating mosses and lichens (Yamakawa et al., 2012; Slavov et al., 2013). This could be a typical photoprotective NPQ mechanism during desiccation (Bilger, 2014) or in certain algae it could be due to a high spillover of energy from PSII to PSI (see e.g., data obtained with algae C. velia Quigg et al., 2012; Kotabová et al., 2014). Further, data of Ruban and Horton (1995) indicate that $\mathrm{pH}$-independent fraction of sustained quenching can be inhibited by the addition of nigericin, a $\mathrm{K}^{+} / \mathrm{H}^{+}$uncoupler. One could speculate that both, i.e., quenching by PSI (due to spill over of excitation energy from PSII to PSI) and $\mathrm{pH}$ independent fraction of sustained quenching are present at low electrostatic screening mode (see Figure 5). However, to confirm these hypotheses, further experiments are needed.

We suggest that the co-regulation of NPQ by both $\mathrm{pH}$ and ions (e.g., by $\mathrm{Mg}^{2+}$ ) is indicated by $\mathrm{Mg}^{2+}$ counter ion transport upon exposure of photosynthetic samples to light (Figure 1) since the accumulation of protons in the lumen is balanced by the efflux of $\mathrm{Mg}^{2+}$ ions to the surface of the thylakoid membrane (Hind et al., 1974; Chow et al., 1976; Ishijima et al., 2003). Moreover, there is data showing the presence of $\mathrm{Mg}^{2+}$ transporter in the chloroplast (Drummond et al., 2006) and light induced changes in $\mathrm{Mg}^{2+}$ concentration (Ishijima et al., 2003). The stimulating role of $\mathrm{Mg}^{2+}$ on protein aggregation in vitro is well known: higher $\mathrm{Mg}^{2+}$ content accelerates reversible quenching of $\mathrm{Chl}$ a fluorescence in isolated antenna by forming aggregates of LHCIIs in vitro (Ruban et al., 1994). This supports the idea that antenna aggregation is a plausible mechanism for $\mathrm{qE}$ quenching (Horton et al., 1991). Similar aggregation induced quenching can be also caused by chemicals having strong effects of membrane impermeable cations such as the polyamines (e.g., petruscine, spermidine, and spermine) on Chl $a$ fluorescence quenching (Ioannidis and Kotzabasis, 2007). These organic compounds are synthesized by living cells, and they can quench the maximal fluorescence in the dark and stimulate NPQ in light in vivo in higher plants (Ioannidis and Kotzabasis, 2007; Ioannidis et al., 2012) and in algae (Ioannidis et al., 2011). This simulation of NPQ seems to be due to antenna aggregation (Tsiavos et al., 2012).

The above-mentioned phenomenon has been confirmed in vivo, and the effect, to a great extent, simulates proton-triggered quenching in isolated antenna (Tsiavos et al., 2012; Malliarakis et al., 2015). Further, this is in agreement with the effect of other tertiary amines-e.g., dibucaine, which has been shown to stimulate NPQ (Ruban et al., 1994; Phillip et al., 1996; Gilmore and Yamasaki, 1998) and bind to thylakoid membrane surfaces (Gilmore and Yamasaki, 1998). $\mathrm{As}_{\mathrm{Mg}^{2+}}$ accumulates on the thylakoid membrane surface when it is exposed to light (Hind et al., 1974), we can speculatethat the cations (polyamines, $\mathrm{Mg}^{2+}$ ) present on the stromal surface could synergistically stimulate $\mathrm{qE}$ (triggered by low lumen $\mathrm{pH}$ ) by allowing antenna aggregation. This type of mechanism would be in line with the presence of a "cation sensitive site" on the stromal side of the thylakoids (Mills et al., 1976). Indeed, one from the subdomain of CP29 antenna from spinach has been proposed to be regulated by chemiosmotic factor (Ioannidis et al., 2016). However, the stimulatory effect of ions on NPQ of fluorescence is, apparently, against the proposed role of $\mathrm{Mg}^{2+}$ in EDL theory (see Figure 4), where $\mathrm{Mg}^{2+}$ induced high screening mode is observed by high $\mathrm{Chl} a$ fluorescence. It seems that there are two quite different mechanisms for cation effects on Chl $a$ fluorescence yield; it could be by direct binding (no fluorescence increase, see Figure 5; possibly stimulating NPQ) or by the effect on EDL (no binding connected with fluorescence increase). However, in any case these contradictory conclusions require new experimental approaches to be used.

\section{GENERAL ASPECTS OF LIGHT-HARVESTING AND ION TRANSPORT}

Protons have distinct effects on the efficiency of the lightharvesting process at the level of excitation energy dissipation of excess light by NPQ of excited state of Chl $a$ molecules (Ruban et al., 2012; Adams et al., 2014; Demmig-Adams et al., 2014; Horton, 2014), whereas, other ions may regulate excitation distribution and redistribution, and stacking of thylakoid membranes (Barber, 1982; Staehelin and Arntzen, 1983; Minagawa, 2011; Papageorgiou and Govindjee, 2011). Protoninduced membrane stacking is a well-known phenomenon 
(Gerola et al., 1979; Jennings et al., 1981a,b). It is caused by neutralization of negative charges on proteins at high proton concentration (see e.g., Barber, 1980a). In photosynthetic cells, these processes are interconnected and light-induced proton pumping is intertwined with counter ion transport (Barber et al., 1974; Hind et al., 1974). Light-induced accumulation of protons in the lumen is balanced mostly by the efflux of $\mathrm{Mg}^{2+}$ ions (Hind et al., 1974; Chow et al., 1976; Ishijima et al., 2003) or $\mathrm{K}^{+}$ ions (Chow et al., 1976; Tester and Blatt, 1989; Carraretto et al., 2013) to the stroma and/or uptake of $\mathrm{Cl}^{-}$ions into the lumen (Hind et al., 1974; Vambutas and Schechter, 1983; Vambutas et al., 1984, 1994). This has been confirmed by the observation of a light-induced increase in $\mathrm{K}^{+}$and $\mathrm{Mg}^{2+}$ concentration in the stroma (Dilley and Vernon, 1965; Hind et al., 1974; Krause, 1977; Portis, 1981), and the accompanying higher $\mathrm{Cl}^{-}$concentration in the lumen (Hind et al., 1974; Vambutas and Schechter, 1983).

It is not yet clear which counter ion is dominant in chloroplasts in vivo since most of the earlier measurements were done on isolated chloroplasts where proton exchange with the cytoplasm could be under-or over-estimated (see e.g., Hind et al., 1974). However, a different major influence of cations has been suggested (see discussion by Cruz et al., 2001) which leads to shrinking of thylakoids after illumination (Dilley and Vernon, 1965; Nobel, 1968). However, there are irreconcilable findings: thylakoid lumen shrinkage (Posselt et al., 2012), and its opposite, a swelling (Kirchhoff et al., 2011). We need an answer to this dilemma. Generally, in most experiments, $\mathrm{Mg}^{2+}$ has been suggested to be the major physiological counterion for $\mathrm{H}^{+}$pumping into the chloroplast (Barber et al., 1974; Hind et al., 1974; Barber, 1976; Enz et al., 1993; Cruz et al., 2001; Ishijima et al., 2003) since another mobile cation, $\mathrm{K}^{+}$, seems to be rather bound or trapped in the chloroplast (Figure 1). Inorganic anions induce state changes in spinach thylakoid membranes (Jajoo et al., 1998) that may indicate a role for $\mathrm{Cl}^{-}$as a counter ion since its transport into the thylakoid lumen could compensate for the $\mathrm{H}^{+}$resulting in thylakoid membrane swelling, observed upon exposure of chloroplasts to light (Kirchhoff et al., 2011). It is also plausible that different counterions behave differently under high/low light. Indeed, counterions for $\mathrm{H}^{+}$pumping are affected by lumen

\section{REFERENCES}

Adams, W. W., Muller, O., Cohu, C. M., and Demmig-Adams, B. (2014). "Photosystem II efficiency and non-photochemical fluorescence quenching in the context of source-sink balance," in Non-Photochemical Quenching and Energy Dissipation in Plants, Algae, and Cyanobacteria, eds B. Demmig-Adams, G. Garab, W. Adams III, and Govindjee (Dordrecht: Springer Netherlands), 503-529.

Åkerlund, H.-E., Andersson, B., Persson, A., and Albertsson, P.-Å. (1979). Isoelectric points of spinach thylakoid membrane surfaces as determined by cross partition. Biochim. Biophys. Acta 552, 238-246. doi: 10.1016/ 0005-2736(79)90280-3

Allen, J. F., Bennett, J., Steinback, K. E., and Arntzen, C. J. (1981). Chloroplast protein-phosphorylation couples plastoquinone redox state to distribution of excitation-energy between photosystems. Nature 291, 25-29. doi: $10.1038 / 291025 \mathrm{a} 0$
$\mathrm{pH}$, which would indicate that different ions act as counterions at low light $\left(\mathrm{Cl}^{-}\right)$and at high light $\left[\mathrm{Mg}^{2+}\right]$ (Ben-Hayyim, 1978).

All the available data support the concept that the role of protons and of all other ions in the regulation of photosynthesis is interconnected since proton/cation antiport (proton/anion symport) is required during photophosphorylation as the electrochemical part of pmf (Ort and Melandri, 1982; Cruz et al., 2001) is reduced in the presence of light in higher plant chloroplasts (Figure 1). This idea is further supported by the fact that stacking of thylakoid membranes can be induced either by high proton or with high $\mathrm{Mg}^{2+}$ concentration (cf. Gerola et al., 1979; Jennings et al., 1979, 1981a,b; Barber, 1980a). Thus, research on the regulation of light-harvesting efficiency requires a new approach when the effects, and mechanisms, of both protons and all other ions will be addressed simultaneously. This is even more important in light of the discovery of several ion channels and transporters in the chloroplast (see, e.g., Carraretto et al., 2013; Armbruster et al., 2014; Hamamoto and Uozumi, 2014; Kunz et al., 2014; Herdean et al., 2016; also see recent reviews by Checchetto et al., 2013; Hanikenne et al., 2014; Pfeil et al., 2014; Finazzi et al., 2015; Xu et al., 2015; Carraretto et al., 2016).

\section{AUTHOR CONTRIBUTIONS}

Both the authors have made substantial, direct and intellectual contribution to the work, and approved it for publication.

\section{ACKNOWLEDGMENTS}

This research was supported by the Czech Science Foundation (project GACR 16-10088S) and by institutional projects Algatech Plus (MSMT LO1416) and Algamic (CZ 1.05/2.1.00/19.0392) by the Czech Ministry of Education, Youth and Sport. We thank George C. Papageorgiou for reading our manuscript and for his many highly valuable suggestions that have improved our review. We are highly grateful to Jim (James) Barber for reading and approving this review. Govindjee thanks the wonderful service he has received from Jeff Haas and all the staff of the Office of Information Technology (Life Sciences; University of Illinois at Urbana-Champaign) during the preparation of this review.

Allen, J. F., and Mullineaux, C. W. (2004). "Probing the mechanism of state transitions in oxygenic photosynthesis by chlorophyll fluorescence spectroscopy, kinetics and imaging," in Chlorophyll a Fluorescence: A Signature of Photosynthesis. Advances in Photosynthesis and Respiration, eds G. C. Papageorgiou, and Govindjee (Dordrecht: Springer), 663-678.

Antal, T. K., Osipov, V., Matorin, D. N., and Rubin, A. B. (2011). Membrane potential is involved in regulation of photosynthetic reactions in the marine diatom Thalassiosira weissflogii. J. Photochem. Photobiol. B.102, 169-173. doi: 10.1016/j.jphotobiol.2010.11.005

Armbruster, U., Carrillo, L. R., Venema, K., Pavlovic, L., Schmidtmann, E., Kornfeld, A., et al. (2014). Ion antiport accelerates photosynthetic acclimation in fluctuating light environments. Nat. Commun. 5:5439. doi: $10.1038 /$ ncomms6439

Barber, J. (1976). "Ionic regulation in intact chloroplasts and its effect on primary photosynthetic processes," in The Intact Chloroplas, ed J. Barber (Amsterdam: Elsevier), 89-134. 
Barber, J. (1980a). An explanation for the relationship between salt-induced thylakoid stacking and the chlorophyll fluorescence changes associated with changes in spillover of energy from photosystem-II to photosystem-I. FEBS Lett. 118, 1-10. doi: 10.1016/0014-5793(80)81207-5

Barber, J. (1980b). Membrane-surface charges and potentials in relation to photosynthesis. Biochim. Biophys. Acta 594, 253-308. doi: 10.1016/0304-4173(80)90003-8

Barber, J. (1982). Influence of surface-charges on thylakoid structure and function. Annu. Rev. Plant Physiol. Plant Mol. Biol. 33, 261-295. doi: 10.1146/annurev.pp.33.060182.001401

Barber, J. (1986). "Regulation of thylakoid membrane structure by surface electrical charge," in Ion Interactions in Energy Transfer Biomembranes, eds G. C. Papageorgiou, J. Barber, and S. Papa (New York, NY: Springer), 15-27.

Barber, J. (1989). "Regulation of thylakoid membrane structure and function by surface electrical charge," in Techniques and New Developments in Photosynthesis Research, eds J. Barber and R. Malkin (New York, NY: Springer), 159-171.

Barber, J., Chow, W. S., Scoufflaire, C., and Lannoye, R. (1980). The relationship between thylakoid stacking and salt induced chlorophyll fluorescence changes. Biochim. Biophys. Acta 591, 92-103. doi: 10.1016/0005-2728(80)90223-6

Barber, J., and Mills, J. (1976). Control of chlorophyll fluorescence by diffuse double-layer. FEBS Lett. 68, 288-292. doi: 10.1016/0014-5793(76)80455-3

Barber, J., Mills, J., and Love, A. (1977). Electrical diffuse layers and their influence on photosynthetic processes. FEBS Lett. 74, 174-181. doi: 10.1016/0014-5793(77)80841-7

Barber, J., Mills, J., and Nicolson, J. (1974). Studies with cation specific ionophores show that within intact chloroplast $\mathrm{Mg}^{++}$acts as main exchange cation for $\mathrm{H}^{+}$ pumping. FEBS Lett. 49, 106-110. doi: 10.1016/0014-5793(74)80643-5

Barber, J., and Searle, G. F. W. (1978). Cation induced increase in chlorophyll fluorescence yield and effect of electrical charge. FEBS Lett. 92, 5-8. doi: 10.1016/0014-5793(78)80708-X

Behrens, C., Hartmann, K., Sunderhaus, S., Braun, H. P., and Eubel, H. (2013). Approximate calculation and experimental derivation of native isoelectric points of membrane protein complexes of Arabidopsis chloroplasts and mitochondria. Biochim. Biophys. Acta Biomembranes 1828, 1036-1046. doi: 10.1016/j.bbamem.2012.11.028

Belgio, E., Duffy, C. D. P., and Ruban, A. V. (2013). Switching light harvesting complex II into photoprotective state involves the lumen-facing apoprotein loop. Phys. Chem. Chem. Phys. 15, 12253-12261. doi: 10.1039/c3cp51925b

Belgio, E., Johnson, M. P., Juric, S., and Ruban, A. V. (2012). Higher plant photosystem II light-harvesting antenna, not the reaction center, determines the excited-state lifetime-both the maximum and the nonphotochemically quenched. Biophys. J. 102, 2761-2771. doi: 10.1016/j.bpj.2012.05.004

Belgio, E., Santabarbara, S., Bína, D., Trsková, E., Herbstová, M., Kaňa, R., et al. (2017). High photochemical trapping efficiency in Photosystem I from the red clade algae Chromera velia and Phaeodactylum tricornutum. Biochim. Biophys. Acta. 1858, 56-63. doi: 10.1016/j.bbabio.2016.10.002

Bellafiore, S., Barneche, F., Peltier, G., and Rochaix, J. D. (2005). State transitions and light adaptation require chloroplast thylakoid protein kinase STN7. Nature 433, 892-895. doi: 10.1038 /nature03286

Ben-Hayyim, G. (1978). $\mathrm{Mg}^{2+}$ translocation across the thylakoid membrane: studies using the ionophore A 23187. Eur. J. Biochem. 83, 99-104. doi: 10.1111/j.1432-1033.1978.tb12072.x

Berg, S., Dodge, S., Krogmann, D. W., and Dilley, R. A. (1974). Chloroplast grana membrane carboxyl groups - their involvement in membrane association. Plant Physiol. 53, 619-627. doi: 10.1104/pp.53.4.619

Bilger, W. (2014). "Desiccation-induced quenching of chlorophyll fluorescence in cryptogams," in Non-Photochemical Quenching and Energy Dissipation in Plants, Algae and Cyanobacteria, eds B. Demmig-Adams, G. Garab, W. Adams, and Govindjee (Dordrecht: Springer), 409-420.

Bonaventura, C., and Myers, J. (1969). Fluorescence and oxygen evolution from chlorella pyrenoidosa. Biochim. Biophys. Acta 189, 366-383. doi: 10.1016/0005-2728(69)90168-6

Briantais, J. M., Vernotte, C., Picaud, M., and Krause, G. H. (1979). Quantitative study of the slow decline of chlorophyll alpha-fluorescence in isolated-chloroplasts. Biochim. Biophys. Acta 548, 128-138. doi: 10.1016/0005-2728(79)90193-2

Carraretto, L., Formentin, E., Teardo, E., Checchetto, V., Tomizioli, M., Morosinotto, T., et al. (2013). A thylakoid-located two-pore K+ channel controls photosynthetic light utilization in plants. Science 342, 114-118. doi: $10.1126 /$ science. 1242113

Carraretto, L., Teardo, E., Checchetto, V., Finazzi, G., Uozumi, N., and Szabo, I. (2016). Ion channels in plant bioenergetic organelles, chloroplasts and mitochondria: from molecular identification to function. Mol. Plant 9, 371-395. doi: 10.1016/j.molp.2015.12.004

Cevc, G. (1990). Membrane electrostatics. Biochim. Biophys. Acta 1031, 311-382. doi: 10.1016/0304-4157(90)90015-5

Checchetto, V., Teardo, E., Carraretto, L., Formentin, E., Bergantino, E., Giacometti, G. M., et al. (2013). Regulation of photosynthesis by ion channels in cyanobacteria and higher plants. Biophys. Chem. 182, 51-57. doi: 10.1016/j.bpc.2013.06.006

Cheregi, O., Kotabová, E., Prášil, O., Schröder, W. P., Kaňa, R., and Funk, C. (2015). Presence of state transitions in the cryptophyte alga Guillardia theta. J. Exp. Bot. 66, 6461-6470. doi: 10.1093/jxb/erv362

Chow, W. S., and Barber, J. (1980). 9-aminoacridine fluorescence changes as a measure of surface-charge density of the thylakoid membrane. Biochim. Biophys. Acta 589, 346-352. doi: 10.1016/0005-2728(80)90050-X

Chow, W. S., Wagner, A. G., and Hope, A. B. (1976). Light-dependent redistribution of ions in isolated spinach chloroplasts. Aust. J. Plant Physiol. 3, 853-861. doi: 10.1071/PP9760853

Consoli, E., Croce, R., Dunlap, D. D., and Finzi, L. (2005). Diffusion of lightharvesting complex II in the thylakoid membranes. EMBO Rep. 6, 782-786. doi: $10.1038 /$ sj.embor.7400464

Croce, R., and Van Amerongen, H. (2014). Natural strategies for photosynthetic light harvesting. Nat. Chem. Biol. 10, 492-501. doi: 10.1038/nchembio.1555

Cruz, J. A., Sacksteder, C. A., Kanazawa, A., and Kramer, D. M. (2001). Contribution of electric field (Delta psi) to steady-state transthylakoid proton motive force (pmf) in vitro and in vivo. Control of pmf parsing into Delta psi and Delta $\mathrm{pH}$ by ionic strength. Biochemistry 40, 1226-1237. doi: $10.1021 /$ bi0018741

Dau, H., and Sauer, K. (1991). Electric-field effect on chlorophyll fluorescence and its relation to photosystem-ii charge separation reactions studied by a salt-jump technique. Biochim. Biophys. Acta 1098, 49-60. doi: 10.1016/0005-2728(91)90008-C

Demmig-Adams, B., Garab, G., Adams, W. W., III, and Govindjee (2014). Non-Photochemical Quenching and Energy Dissipation in Plants, Algae and Cyanobacteria. Dordrecht: Springer.

Dilley, R. A. (2004). On why thylakoids energize ATP formation using either delocalized or localized proton gradients - a Ca2+ mediated role in thylakoid stress responses. Photosyn. Res. 80, 245-263. doi: 10.1023/B:PRES.0000030436.32486.aa

Dilley, R. A., and Vernon, L. P. (1965). Ion and water transport processes related to the light-dependent shrinkage of spinach chloroplasts. Arch. Biochem. Biophys. 111, 365-375. doi: 10.1016/0003-9861(65)90198-0

Drummond, R. S. M., Tutone, A., Li, Y. C., and Gardner, R. C. (2006). A putative magnesium transporter AtMRS2-11 is localized to the plant chloroplast envelope membrane system. Plant Sci. 170, 78-89. doi: 10.1016/j.plantsci.2005.08.018

Duysens, L. N. M. (1972). 3-(3,4-dichlorophenyl)-1,1-dimethylurea (dcmu) inhibition of system II and light-induced regulatory changes in energytransfer efficiency. Biophys. J. 12, 858-863. doi: 10.1016/S0006-3495(72) 86129-0

Enz, C., Steinkamp, T., and Wagner, R. (1993). Ion channels in the thylakoid membrane (a patch-clamp study). Biochim. Biophys. Acta 1143, 67-76. doi: 10.1016/0005-2728(93)90217-4

Finazzi, G., Petroutsos, D., Tomizioli, M., Flori, S., Sautron, E., Villanova, V., et al. (2015). Ions channels/transporters and chloroplast regulation. Cell Calcium 58, 86-97. doi: 10.1016/j.ceca.2014.10.002

Fristedt, R., Granath, P., and Vener, A. V. (2010). A protein phosphorylation threshold for functional stacking of plant photosynthetic membranes. PLoS ONE 5:e10963. doi: 10.1371/journal.pone.0010963

Gerola, P. D., Jennings, R. C., Forti, G., and Garlaschi, F. M. (1979). Influence of protons on thylakoid membrane stacking. Plant Sci. Lett. 16, 249-254. doi: 10.1016/0304-4211(79)90035-X

Gilmore, A. M., Hazlett, T. L., and Govindjee (1995). Xanthophyll cycle-dependent quenching of photosystem-ii chlorophyll-a fluorescence - formation of a quenching complex with a short fluorescence lifetime. Proc. Natl. Acad. Sci. U.S.A. 92, 2273-2277. doi: 10.1073/pnas.92.6.2273 
Gilmore, A. M., and Yamasaki, H. (1998). 9-aminoacridine and dibucaine exhibit competitive interactions and complicated inhibitory effects that interfere with measurements of Delta $\mathrm{pH}$ and xanthophyll cycle-dependent photosystem II energy dissipation. Photosyn. Res. 57, 159-174. doi: 10.1023/A:1006065931183

Giovagnetti, V., Ware, M. A., and Ruban, A. V. (2015). Assessment of the impact of photosystem I chlorophyll fluorescence on the pulse-amplitude modulated quenching analysis in leaves of Arabidopsis thaliana. Photosyn. Res. 125, 179-189. doi: 10.1007/s11120-015-0087-z

Goldschmidt-Clermont, M., and Bassi, R. (2015). Sharing light between two photosystems: mechanism of state transitions. Curr. Opin. Plant Biol. 25, 71-78. doi: 10.1016/j.pbi.2015.04.009

Govindjee (2004). "Chlorophyll a fluorescence: a bit of basics and history," in Chlorophyll a Fluorescence: A Signature of Photosynthesis, eds G. C. Papageorgiou and Govindjee (Dordrecht: Springer Netherlands), 1-41.

Govindjee and Björn, L. (2012). "Dissecting oxygenic photosynthesis: the evolution of the "Z"-scheme for thylakoid reactions," in Photosynthesis: Overviews on Recent Progress and Future Perspective, eds S. Itoh, P. Mohanty, and K. N. Guruprasad (New Delhi: I.K. Publishers), 1-27.

Govindjee, Wong, D., Prezelin, B. B., and Sweeney, B. M. (1979). Chlorophyll a fluorescence of Gonyaulax polydera grown on a light-dark cycle and after transfer to constant light. Photochem. Photobiol. 30, 405-411.

Gross, E. L., and Hess, S. C. (1973). Monovalent cation-induced inhibition of chlorophyll a fluorescence: antagonism by divalent cations. Arch. Biochem. Biophys. 159, 832-836. doi: 10.1016/0003-9861(73)90524-9

Hamamoto, S., and Uozumi, N. (2014). Organelle-localized potassium transport systems in plants. J. Plant Physiol. 171, 743-747. doi: 10.1016/j.jplph.2013. 09.022

Hanikenne, M., Bernal, M., and Urzica, E. I. (2014). Ion homeostasis in the Chloroplast. New York, NY: Springer.

Herdean, A., Teardo, E., Nilsson, A. K., Pfeil, B. E., Johansson, O. N., Ünnep, R., et al. (2016). A voltage-dependent chloride channel fine-tunes photosynthesis in plants. Nature Commun. 7:11654. doi: 10.1038/ncomms11654

Hind, G., Nakatani, H. Y., and Izawa, S. (1974). Light-dependent redistribution of ions in suspensions of chloroplast thylakoid membranes. Proc. Natl. Acad. Sci. U.S.A. 71, 1484-1488. doi: 10.1073/pnas.71.4.1484

Horton, P. (2014). "Developments in research on non-photochemical fluorescence quenching: emergence of key ideas, Theories and Experimental Approaches," in Non-Photochemical Quenching and Energy Dissipation in Plants, Algae and Cyanobacteria, eds B. Demmig-Adams, G. Garab, W. Adams III, and Govindjee (Dordrecht: Springer Netherlands), 73-95.

Horton, P., and Black, M. T. (1980). Activation of adenosine 5'-triphosphateinduced quenching of chlorophyll fluorescence by reduced plastoquinone the basis of state-i-state-ii transitions in chloroplasts. FEBS Lett. 119, 141-144. doi: 10.1016/0014-5793(80)81016-7

Horton, P., Ruban, A. V., Rees, D., Pascal, A. A., Noctor, G., and Young, A. J. (1991). Control of the light-harvesting function of chloroplast membranes by aggregation of the LHCII chlorophyll-protein complex. FEBS Letters 292, 1-4.

Horton, P., Ruban, A. V., and Walters, R. G. (1996). Regulation of light harvesting in green plants. Annu. Rev. Plant Physiol. Plant Mol. Biol. 47, 655-684. doi: 10.1146/annurev.arplant.47.1.655

Ioannidis, N. E., and Kotzabasis, K. (2007). Effects of polyamines on the functionality of photosynthetic membrane in vivo and in vitro. Biochim. Biophys. Acta Bioenerg. 1767, 1372-1382. doi: 10.1016/j.bbabio.2007.10.002

Ioannidis, N. E., Lopera, O., Santos, M., Torne, J. M., and Kotzabasis, K. (2012). Role of plastid transglutaminase in LHCII polyamination and thylakoid electron and proton flow. PLOS ONE 7:e41979. doi: 10.1371/journal.pone.0041979

Ioannidis, N. E., Papadatos, S., and Daskalakis, V. (2016). Energizing the light harvesting antenna: insight from CP29. Biochim. Biophys. Acta Bioenerg. 1857, 1643-1650. doi: 10.1016/j.bbabio.2016.07.005

Ioannidis, N. E., Sfichi-Duke, L., and Kotzabasis, K. (2011). Polyamines stimulate non-photochemical quenching of chlorophyll a fluorescence in Scenedesmus obliquus. Photosyn. Res. 107, 169-175. doi: 10.1007/s11120-010-9617-x

Ishijima, S., Uchlbori, A., Takagi, H., Maki, R., and Ohnishi, M. (2003). Lightinduced increase in free $\mathrm{Mg} 2+$ concentration in spinach chloroplasts: measurement of free $\mathrm{Mg} 2+$ by using a fluorescent probe and necessity of stromal alkalinization. Arch. Biochem. Biophys. 412, 126-132. doi: 10.1016/S0003-9861(03)00038-9
Ivanov, A. G., Sane, P. V., Hurry, V., Oquist, G., and Huner, N. P. A. (2008) Photosystem II reaction centre quenching: mechanisms and physiological role. Photosyn. Res. 98, 565-574. doi: 10.1007/s11120-008-9365-3

Izawa, S., and Good, N. E. (1966). Effect of salts and electron transport on conformation of isolated chloroplasts.i. Light-scattering and volume changes. Plant Physiol. 41, 533-543. doi: 10.1104/pp.41.3.533

Jajoo, A., and Bharti, S. (1999). Interaction of anions and cations in regulating energy distribution between the two photosystems. Photosynthetica 37, 529-535. doi: 10.1023/A:1007159105734

Jajoo, A., Bharti, S., and Govindjee (1998). Inorganic anions induce state changes in spinach thylakoid membranes. FEBS Lett. 434, 193-196. doi: 10.1016/S0014-5793(98)00978-8

Jajoo, A., Bharti, S., and Mohanty, P. (2001). Evaluation of the specific roles of anions in electron transport and energy transfer reactions in photosynthesis. Photosynthetica 39, 321-337. doi: 10.1023/A:1015125008028

Janik, E., Bednarska, J., Zubik, M., Puzio, M., Luchowski, R., Grudzinski, W., et al. (2013). Molecular architecture of plant thylakoids under physiological and light stress conditions: a study of lipid-light-harvesting complex II model membranes. Plant Cell 25, 2155-2170. doi: 10.1105/tpc.113. 113076

Jennings, R. C., Garlaschi, F. M., Gerola, P. D., Etzionkatz, R., and Forti, G. (1981a). Proton-induced grana formation in chloroplasts - distribution of chlorophyllprotein complexes and photosystem-ii photochemistry. Biochim. Biophys. Acta 638, 100-107. doi: 10.1016/0005-2728(81)90191-2

Jennings, R. C., Gerola, P. D., Forti, G., and Garlaschi, F. M. (1979). Influence of proton-induced grana formation on partial electron-transport reactions in chloroplasts. FEBS Lett. 106, 247-250. doi: 10.1016/0014-5793(79)80738-3

Jennings, R. C., Gerola, P. D., Garlaschi, F. M., and Forti, G. (1981b). Effects of trypsin and cations on chloroplast membranes. Plant Physiol. 67, 212-215. doi: 10.1104/pp.67.2.212

Jennings, R. C., Gerola, P. D., Garlaschi, F. M., and Forti, G. (1982). Studies on the kinetics of cation-associated fluorescence changes in chloroplast membranes. FEBS Lett. 142, 167-170. doi: 10.1016/0014-5793(82)80244-5

Johnson, M. P., and Ruban, A. V. (2010). Arabidopsis plants lacking PsbS protein possess photoprotective energy dissipation. Plant J. 61, 283-289. doi: 10.1111/j.1365-313X.2009.04051.x

Johnson, M. P., and Ruban, A. V. (2014). Rethinking the existence of a steadystate Delta psi component of the proton motive force across plant thylakoid membranes. Photosyn. Res. 119, 233-242. doi: 10.1007/s11120-013-9817-2

Junge, W. (2004). Protons, proteins and ATP. Photosyn. Res. 80, 198-221. doi: 10.1023/B:PRES.0000030677.98474.74

Junge, W. (2013). Half a century of molecular bioenergetics. Biochem. Soc. Trans. 41, 1207-1218. doi: 10.1042/BST20130199

Junge, W., and Nelson, N. (2015). “ATP Synthase," in Annual Review of Biochemistry, Vol 84, ed R. D. Kornberg (Palo Alto, CA: Annual Reviews), 631-657.

Junge, W., Reinwald, E., Rumberg, B., Siggel, U., and Witt, H. T. (1968). Further evidence for a new function unit of photosynthesis. Naturwissenschaften 55, 36-37. doi: 10.1007/BF00593410

Junge, W., Rumberg, B., and Schroder, H. (1970). Necessity of an electric potential difference and its use for photophosphorylation in short flash groups. Eur. J. Biochem. 14, 575-581. doi: 10.1111/j.1432-1033.1970.tb00326.x

Junge, W., and Witt, H. T. (1968). On ion transport system of photosynthesis - investigations on a molecular level. Z. Naturforsch. B 23, 244-254. doi: 10.1515/znb-1968-0222

Kaňa, R. (2013). Mobility of photosynthetic proteins. Photosyn. Res. 116, 465-479. doi: 10.1007/s11120-013-9898-y

Kaňa, R., Kotabová, E., Komárek, O., Šedivá, B., Papageorgiou, G. C., Govindjee et al. (2012a). The slow $S$ to $M$ fluorescence rise in cyanobacteria is due to a state 2 to state 1 transition. Biochim. Biophys. Acta 1817, 1237-1247. doi: 10.1016/j.bbabio.2012.02.024

Kaňa, R., Kotabová, E., Kopečná, J., Trsková, E., Belgio, E., Sobotka, R., et al. (2016). Violaxanthin inhibits nonphotochemical quenching in light-harvesting antenna of Chromera velia. FEBS Lett. 590, 1076-1085. doi: 10.1002/1873-3468.12130

Kaňa, R., Kotabová, E., Lukeš, M., Papáček, Š., Matonoha, C., Liu, L.-N., et al. (2014). Phycobilisome mobility and its role in the regulation of light harvesting in Red Algae. Plant Physiol. 165, 1618-1631. doi: 10.1104/pp.114.236075 
Kaňa, R., Kotabová, E., and Prášil, O. (2008). Acceleration of plastoquinone pool reduction by alternative pathways precedes a decrease in photosynthetic $\mathrm{CO}(2)$ assimilation in preheated barley leaves. Physiol. Plant. 133, 794-806. doi: 10.1111/j.1399-3054.2008.01094.x

Kaňa, R., Kotabová, E., Sobotka, R., and Prášil, O. (2012b). Non-photochemical quenching in cryptophyte alga rhodomonas salina is located in chlorophyll a/c Antennae. PLoS ONE 7:e29700. doi: 10.1371/journal.pone.0029700

Kaňa, R., Prášil, O., Komárek, O., Papageorgiou, G. C., and Govindjee (2009). Spectral characteristic of fluorescence induction in a model cyanobacterium, Synechococcus sp (PCC 7942). Biochim. Biophys. Acta 1787, 1170-1178. doi: 10.1016/j.bbabio.2009.04.013

Kaňa, R., and Vass, I. (2008). Thermoimaging as a tool for studying lightinduced heating of leaves Correlation of heat dissipation with the efficiency of photosystem II photochemistry and non-photochemical quenching. Environ. Exp. Bot. 64, 90-96. doi: 10.1016/j.envexpbot.2008.02.006

Karge, O., Bondar, A. N., and Dau, H. (2014). Cationic screening of charged surface groups (carboxylates) affects electron transfer steps in photosystem-II water oxidation and quinone reduction. Biochim. Biophys. Acta Bioenerg. 1837, 1625-1634. doi: 10.1016/j.bbabio.2014.07.012

Kasumov, E. A., Kasumov, R. E., and Kasumova, I. V. (2015). A mechanochemiosmotic model for the coupling of electron and proton transfer to ATP synthesis in energy-transforming membranes: a personal perspective. Photosyn. Res. 123, 1-22. doi: 10.1007/s11120-014-0043-3

Khan, S., Sun, J. S., and Brudvig, G. W. (2015). Cation effects on the electron-acceptor side of photosystem II. J. Phys. Chem. B 119, 7722-7728. doi: $10.1021 /$ jp $513035 \mathrm{u}$

Kirchhoff, H. (2014). Diffusion of molecules and macromolecules in thylakoid membranes. Biochim. Biophys. Acta Bioenerg. 1837, 495-502. doi: 10.1016/j.bbabio.2013.11.003

Kirchhoff, H., Borinski, M., Lenhert, S., Chi, L. F., and Buchel, C. (2004). Transversal and lateral exciton energy transfer in grana thylakoids of spinach. Biochemistry 43, 14508-14516. doi: 10.1021/bi048473w

Kirchhoff, H., Hall, C., Wood, M., Herbstova, M., Tsabari, O., Nevo, R., et al. (2011). Dynamic control of protein diffusion within the granal thylakoid lumen. Proc. Natl. Acad. Sci. U.S.A. 108, 20248-20253. doi: $10.1073 /$ pnas.1104141109

Kirchhoff, H., Hinz, H. R., and Rosgen, J. (2003). Aggregation and fluorescence quenching of chlorophyll a of the light-harvesting complex II from spinach in vitro. Biochim. Biophys. Acta Bioenerg. 1606, 105-116. doi: 10.1016/S0005-2728(03)00105-1

Kirilovsky, D., Kaňa, R., and Prášil, O. (2014). "Mechanisms modulating energy arriving at reaction centers in cyanobacteria," in Non-Photochemical Quenching and Energy Dissipation in Plants, Algae and Cyanobacteria, eds. B. DemmigAdams, G. Garab, W. Adams III, and Govindjee (Dordrecht: Springer Netherlands), 471-501.

Kiss, A. Z., Ruban, A. V., and Horton, P. (2008). The PsbS protein controls the organization of the photosystem II antenna in higher plant thylakoid membranes. J. Biol. Chem. 283, 3972-3978. doi: 10.1074/jbc.M707410200

Kobližek, M., Kaftan, D., and Nedbal, L. (2001). On the relationship between the non-photochemical quenching of the chlorophyll fluorescence and the Photosystem II light harvesting efficiency. A repetitive flash fluorescence induction study. Photosyn. Res. 68, 141-152. doi: 10.1023/A:1011830015167

Kodru, S., Malavath, T., Devadasu, E., Nellaepalli, S., Stirbet, A., Subramanyam, R., et al. (2015). The slow $\mathrm{S}$ to $\mathrm{M}$ rise of chlorophyll $a$ fluorescence reflects transition from state 2 to state 1 in the green alga Chlamydomonas reinhardtii. Photosynth. Res. 125, 219-231. doi: 10.1007/s11120-015-0084-2

Kolber, Z. S., Prášil, O., and Falkowski, P. G. (1998). Measurements of variable chlorophyll fluorescence using fast repetition rate techniques: defining methodology and experimental protocols. Biochim. Biophys. Acta Bioenerg. 1367, 88-106. doi: 10.1016/S0005-2728(98)00135-2

Kotabová, E., Jarešová, J., Kaňa, R., Sobotka, R., Bína, D., and Prášil, O. (2014). Novel type of red-shifted chlorophyll $a$ antenna complex from Chromera velia. I. Physiological relevance and functional connection to photosystems. Biochim. Biophys. Acta 1837, 734-743. doi: 10.1016/j.bbabio.2014.01.012

Kramer, D. M., Avenson, T. J., and Edwards, G. E. (2004). Dynamic flexibility in the light reactions of photosynthesis governed by both electron and proton reactions. Trends Plant Sci. 9, 349-357. doi: 10.1016/j.tplants.2004.05.001

Kramer, D. M., Sacksteder, C. A., and Cruz, J. A. (1999). How acidic is the lumen? Photosyn. Res. 60, 151-163. doi: 10.1023/A:1006212014787
Krause, G. H. (1977). Light-induced movement of magnesium ions in intact chloroplasts. Spectroscopic determination with Eriochrome Blue SE. Biochim. Biophys. Acta 460, 500-510. doi: 10.1016/0005-2728(77)90088-3

Krause, G. H. (1988). Photoinhibition of photosynthesis - an evaluation of damaging and protective mechanisms. Physiol. Plant. 74, 566-574. doi: 10.1111/j.1399-3054.1988.tb02020.x

Krause, G. H., Briantais, J. M., and Vernotte, C. (1983). Characterization of chlorophyll fluorescence quenching in chloroplasts by fluorescence spectroscopy at 77-K.1. Delta-ph-dependent quenching. Biochim. Biophys. Acta 723, 169-175. doi: 10.1016/0005-2728(83)90116-0

Krause, G. H., and Jahns, P. (2004). "Non-photochemical energy dissipation determined by chlorophyll fluorescence quenching: characterization and function," in Chlorophyll a Fluorescence: A Signature of Photosynthesis, eds G. C. Papageorgiou and Govindjee (Dordrecht: Springer Netherlands), 463-495.

Krause, G. H., and Weis, E. (1991). Chlorophyll fluorescence and photosynthesis - the basics. Annu. Rev. Plant Physiol. Plant Mol. Biol. 42, 313-349. doi: 10.1146/annurev.pp.42.060191.001525

Krupenina, N. A., and Bulychev, A. A. (2007). Action potential in a plant cell lowers the light requirement for non-photochemical energy-dependent quenching of chlorophyll fluorescence. Biochim. Biophys. Acta 1767, 781-788. doi: 10.1016/j.bbabio.2007.01.004

Krupnik, T., Kotabová, E., Van Bezouwen, L. S., Mazur, R., Garstka, M., Nixon, P. J., et al. (2013). A reaction centre-dependent photoprotection mechanism in a highly robust photosystem II from an extremophilic red alga Cyanidioschyzon merolae. J. Biol. Chem. 288, 23529-23542. doi: 10.1074/jbc.M113.484659

Kunz, H. H., Gierth, M., Herdean, A., Satoh-Cruz, M., Kramer, D. M., Spetea, C., et al. (2014). Plastidial transporters KEA1, -2, and -3 are essential for chloroplast osmoregulation, integrity, and $\mathrm{pH}$ regulation in Arabidopsis. Proc. Natl. Acad. Sci. U.S.A. 111, 7480-7485. doi: 10.1073/pnas.1323899111

Lazár, D. (1999). Chlorophyll a fluorescence induction. Biochim. Biophys. Acta Bioenerg. 1412, 1-28.

Lazár, D. (2006). The polyphasic chlorophyll a fluorescence rise measured under high intensity of exciting light. Funct. Plant Biol. 33, 9-30. doi: 10.1071/FP05095

Li, X. P., Bjorkman, O., Shih, C., Grossman, A. R., Rosenquist, M., Jansson, S., et al. (2000). A pigment-binding protein essential for regulation of photosynthetic light harvesting. Nature 403, 391-395. doi: 10.1038/35000131

Lyu, H., and Lazár, D. (2017). Modeling the light-induced electric potential difference $(\Delta \Psi)$, the $\mathrm{pH}$ difference $(\Delta \mathrm{pH})$ and the proton motive force across the thylakoid membrane in C3 leaves. J. Theor. Biol. 413, 11-23. doi: $10.1016 /$ j.jtbi.2016.10.017

Malliarakis, D., Tsiavos, T., Ioannidis, N. E., and Kotzabasis, K. (2015). Spermine and lutein quench chlorophyll fluorescence in isolated PSII antenna complexes. J. Plant Physiol. 183, 108-113. doi: 10.1016/j.jplph.2015.06.006

Mills, J. D., and Barber, J. (1978). Fluorescence changes in isolated broken chloroplasts and involvement of electrical double-layer. Biophys. J. 21, 257-272. doi: 10.1016/S0006-3495(78)85523-4

Mills, J. D., Telfer, A., and Barber, J. (1976). Cation control of chlorophyll-alpha fluorescence yield in chloroplasts - location of cation sensitive sites. Biochim. Biophys. Acta 440, 495-505. doi: 10.1016/0005-2728(76)90037-2

Minagawa, J. (2011). State transitions-The molecular remodeling of photosynthetic supercomplexes that controls energy flow in the chloroplast. Biochim. Biophys. Acta Bioenerg. 1807, 897-905. doi: 10.1016/j.bbabio.2010.11.005

Mirkovic, T., Ostroumov, E. E., Anna, J. M., Van Grondelle, R., Govindjee, and Scholes, G. D. (2016). Light absorption and energy transfer in the antenna complexes of photosynthetic organisms. Chem. Rev. doi: 10.1021/acs.chemrev.6b00002. [Epub ahead of print].

Mitchell, P. (1961). Coupling of phosphorylation to electron and hydrogen transfer by a chemi-osmotic type of mechanism. Nature 191, 144-148. doi: $10.1038 / 191144 \mathrm{a} 0$

Mitchell, P. (1966). Chemiosmotic coupling in oxidative and photosynthetic phosphorylation. Biol. Rev. Camb. Philos. Soc. 41, 445-502. doi: 10.1111/j.1469-185X.1966.tb01501.x

Mizusawa, N., and Wada, H. (2012). The role of lipids in photosystem II. Biochim. Biophys. Acta Bioenerg. 1817, 194-208. doi: 10.1016/j.bbabio.2011.04.008

Mohanty, P., Braun, B. Z., and Govindje (1973). Light-induced slow changes in chlorophyll a fluorescence in isolated chloroplasts - effects of magnesium and phenazine methosulfate. Biochim. Biophys. Acta 292, 459-476. doi: 10.1016/0005-2728(73)90051-0 
Mohanty, P., Govindje, and Wydrzynski, T. (1974). Salt-induced alterations of fluorescence yield and of emission-spectra in chlorella-pyrenoidosa. Plant Cell Physiol. 15, 213-224.

Mulkidjanian, A. Y., Heberle, J., and Cherepanov, D. A. (2006). Protons @ interfaces: implications for biological energy conversion. Biochim. Biophys. Acta Bioenerg. 1757, 913-930. doi: 10.1016/j.bbabio.2006.02.015

Mullineaux, C. W. (2008). Factors controlling the mobility of photosynthetic proteins. Photochem. Photobiol. 84, 1310-1316. doi: 10.1111/j.1751-1097.2008.00420.x

Mullineaux, C. W., and Allen, J. F. (1986). The state-2 transition in the Cyanobacterium Synechococcus-6301 can be driven by respiratory electron flow into the plastoquinone pool. FEBS Lett. 205, 155-160. doi: 10.1016/0014-5793(86)80885-7

Murata, N. (1969a). Control of excitation transfer in photosynthesis.2. Magnesium ion-dependent distribution of excitation energy between 2 pigment systems in spinach chloroplasts. Biochim. Biophys. Acta 189, 171-181. doi: 10.1016/0005-2728(69)90045-0

Murata, N. (1969b). Control of excitation transfer in photosynthesis. I. Lightinduced change of chlorophyll $a$ fluorescence in Porphyridium cruentum. Biochim. Biophys. Acta 172, 242-251. doi: 10.1016/0005-2728(69)90067-X

Nagy, G., Uennep, R., Zsiros, O., Tokutsu, R., Takizawa, K., Porcar, L., et al. (2014). Chloroplast remodeling during state transitions in Chlamydomonas reinhardtii as revealed by noninvasive techniques in vivo. Proc. Natl. Acad. Sci. U.S.A. 111, 5042-5047. doi: 10.1073/pnas.1322494111

Nakatani, H. Y., and Barber, J. (1980). Further-studies of the thylakoid membranesurface charges by particle electrophoresis. Biochim. Biophys. Acta 591, 82-91. doi: 10.1016/0005-2728(80)90222-4

Nakatani, H. Y., Barber, J., and Forrester, J. A. (1978). Surface charges on chloroplast membranes as studied by particle electrophoresis. Biochim. Biophys. Acta 504, 215-225. doi: 10.1016/0005-2728(78)90019-1

Nilkens, M., Kress, E., Lambrev, P., Miloslavina, Y., Muller, M., Holzwarth, A. R., et al. (2010). Identification of a slowly inducible zeaxanthin-dependent component of non-photochemical quenching of chlorophyll fluorescence generated under steady-state conditions in Arabidopsis. Biochim. Biophys. Acta Bioenerg. 1797, 466-475. doi: 10.1016/j.bbabio.2010.01.001

Niyogi, K. K., Grossman, A. R., and Bjorkman, O. (1998). Arabidopsis mutants define a central role for the xanthophyll cycle in the regulation of photosynthetic energy conversion. Plant Cell 10, 1121-1134. doi: $10.1105 /$ tpc.10.7.1121

Nobel, P. S. (1968). Chloroplast shrinkage and increased photophosphorylation in vitro upon illuminating intact plants of Pisum sativum. Biochim. Biophys. Acta 153, 170-182. doi: 10.1016/0005-2728(68)90157-6

Noctor, G., Ruban, A. V., and Horton, P. (1993). Modulation of delta-phdependent nonphotochemical quenching of chlorophyll fluorescence in spinach-chloroplasts. Biochim. Biophys. Acta 1183, 339-344. doi: 10.1016/0005-2728(93)90237-A

Ocampo-Alvarez, H., García-Mendoza, E., and Govindjee (2013). Antagonist effect between violaxanthin and de-epoxidated pigments in nonphotochemical quenching induction in the $\mathrm{qE}$ deficient brown alga Macrocystis pyrifera. Biochim. Biophys. Acta 1827, 427-437. doi: 10.1016/j.bbabio.2012.12.006

Ogawa, T., Grantz, D., Boyer, J., and Govindjee (1982). Effects of cations and abscisic-acid on chlorophyll a fluorescence in guard-cells of Vicia-faba. Plant Physiol. 69, 1140-1144. doi: 10.1104/pp.69.5.1140

Ort, D. R., and Melandri, B. A. (1982). "12 - Mechanism of ATP Synthesis*," in Photosynthesis: Energy Conversion by Plants and Bacteria (Cell Biology), ed Govindjee (New York, NY: Academic Press), 537-587.

Ostroumov, E., Khan, Y., Scholes, G., and Govindjee (2014). "Photophysics of Photosynthetic Pigment-Protein Complexes," in Non-Photochemical Quenching and Energy Dissipation in Plants, Algae and Cyanobacteria, eds B. DemmigAdams, G. Garab, W. Adams III, and Govindjee (Dordrecht: Springer Netherlands), 97-128.

Papageorgiou, C. G., and Stamatakis, K. (2004). "Water and solute transport in cyanobacteria as probed by chlorophyll fluorescence," in Chlorophyll a Fluorescence: A Signature of Photosynthesis, eds G. C. Papageorgiou and Govindjee (Dordrecht: Springer), 663-678.

Papageorgiou, G. C., and Govindjee, (2011). Photosystem II fluorescence: slow changes - Scaling from the past. J. Photochem. Photobiol. B Biol. 104, 258-270. doi: 10.1016/j.jphotobiol.2011.03.008
Papageorgiou, G., and Govindjee (1968a). Light-induced changes in fluorescence yield of chlorophyll alpha in vivo.I. Anacystis nidulans. Biophys. J. 8, 1299-1315. doi: 10.1016/S0006-3495(68)86557-9

Papageorgiou, G., and Govindjee (1968b). Light-induced changes in the fluorescence yield of chlorophyll a in vivo: II. Chlorella pyrenoidosa. Biophys. J. 8, 1316-1328. doi: 10.1016/S0006-3495(68)86558-0

Papageorgiou, G., and Govindjee (2004). Chlorophyll a Fluorescence: A Signature of Photosynthesis. Dordrecht: Springer.

Pfeil, B. E., Schoefs, B., and Spetea, C. (2014). Function and evolution of channels and transporters in photosynthetic membranes. Cell. Mol. Life Sci. 71, 979-998. doi: 10.1007/s00018-013-1412-3

Phillip, D., Ruban, A. V., Horton, P., Asato, A., and Young, A. J. (1996). Quenching of chlorophyll fluorescence in the major light-harvesting complex of photosystem II: a systematic study of the effect of carotenoid structure. Proc. Natl. Acad. Sci. U.S.A. 93, 1492-1497. doi: 10.1073/pnas.93.4.1492

Portis, A. R. (1981). Evidence of a low stromal $\mathrm{mg}$ concentration in intact chloroplasts in the dark: i. studies with the ionophore A23187. Plant Physiol. 67, 985-989. doi: 10.1104/pp.67.5.985

Pospišil, P., and Dau, H. (2002). Valinomycin sensitivity proves that lightinduced thylakoid voltages result in millisecond phase of chlorophyll fluorescence transients. Biochim. Biophys. Acta Bioenerg. 1554, 94-100. doi: 10.1016/S0005-2728(02)00216-5

Posselt, D., Nagy, G., Kirkensgaard, J. J. K., Holm, J. K., Aagaard, T. H., Timmins, P., et al. (2012). Small-angle neutron scattering study of the ultrastructure of chloroplast thylakoid membranes - Periodicity and structural flexibility of the stroma lamellae. Biochim. Biophys. Acta 1817, 1220-1228. doi: 10.1016/j.bbabio.2012.01.012

Prášil, O., Adir, N., and Ohad, I. (1992). "Dynamics of Photosystem II: mechanism of photoinhibition and recovery processes," in The Photosystems: Structure, Function and Molecular Biology, ed J. Barber (Oxford: Elsevier Science), 295-348.

Quigg, A., Kotabová, E., Jarešová, J., Kaňa, R., Šetlik, J., Šediva, B., et al. (2012). Photosynthesis in Chromera velia represents a simple system with high efficiency. PLoS ONE 7:e47036. doi: 10.1371/journal.pone.0047036

Ruban, A. V., and Horton, P. (1995). An investigation of the sustained component of nonphotochemical quenching of chlorophyll fluorescence in isolated-chloroplasts and leaves of spinach. Plant Physiol. 108, 721-726. doi: 10.1104/pp.108.2.721

Ruban, A. V., and Johnson, M. P. (2009). Dynamics of higher plant photosystem cross-section associated with state transitions. Photosyn. Res. 99, 173-183. doi: 10.1007/s11120-008-9387-x

Ruban, A. V., Johnson, M. P., and Duffy, C. D. P. (2012). The photoprotective molecular switch in the photosystem II antenna. Biochim. Biophys. Acta 1817, 167-181. doi: 10.1016/j.bbabio.2011.04.007

Ruban, A. V., Young, A., and Horton, P. (1994). Modulation of chlorophyll fluorescence quenching in isolated light-harvesting complex of photosystem-II. Biochim. Biophys. Acta Bioenerg. 1186, 123-127. doi: 10.1016/0005-2728(94)90143-0

Rubin, B. T., and Barber, J. (1980). The role of membrane-surface charge in the control of photosynthetic processes and the involvement of electrostatic screening. Biochim. Biophys. Acta 592, 87-102. doi: 10.1016/0005-2728(80)90116-4

Rumak, I., Gieczewska, K., Kierdaszuk, B., Gruszecki, W. I., Mostowska, A., Mazur, R., et al. (2010). 3-D modelling of chloroplast structure under $(\mathrm{Mg} 2+)$ magnesium ion treatment. Relationship between thylakoid membrane arrangement and stacking. Biochim. Biophys. Acta Bioenerg.1797, 1736-1748. doi: 10.1016/j.bbabio.2010.07.001

Samson, G., Prasil, O., and Yaakoubd, B. (1999). Photochemical and thermal phases of chlorophyll a fluorescence. Photosynthetica 37, 163-182. doi: 10.1023/A:1007095619317

Schaller, S., Latowski, D., Jemiola-Rzeminska, M., Dawood, A., Wilhelm, C. Strzalka, K., et al. (2011). Regulation of LHCII aggregation by different thylakoid membrane lipids. Biochim. Biophys. Acta Bioenerg. 1807, 326-335. doi: 10.1016/j.bbabio.2010.12.017

Schaller, S., Richter, K., Wilhelm, C., and Goss, R. (2014). Influence of pH, $\mathrm{Mg} 2+$, and lipid composition on the aggregation state of the diatom FCP in comparison to the LHCII of vascular plants. Photosyn. Res. 119, 305-317. doi: $10.1007 / \mathrm{s} 11120-013-9951-\mathrm{x}$ 
Schansker, G., Toth, S. Z., Holzwarth, A. R., and Garab, G. (2014). Chlorophyll a fluorescence: beyond the limits of the Q(A) model. Photosyn. Res. 120, 43-58. doi: 10.1007/s11120-013-9806-5

Schansker, G., Toth, S. Z., Kovacs, L., Holzwarth, A. R., and Garab, G. (2011). Evidence for a fluorescence yield change driven by a light-induced conformational change within photosystem II during the fast chlorophyll a fluorescence rise. Biochim. Biophys. Acta Bioenerg. 1807, 1032-1043. doi: 10.1016/j.bbabio.2011.05.022

Schliephake, W., Junge, W., and Witt, H. T. (1968). Correlation between field formation proton translocation and light reactions in photosynthesis. $Z$. Naturforsch. B 23, 1571-1578. doi: 10.1515/znb-1968-1203

Scoufflaire, C., Lannoye, R., and Barber, J. (1982). Chlorophyll fluorescence and thylakoid stacking changes - electrostatic screening versus charge neutralization. Photobiochem. Photobiophys. 4, 249-256.

Slavov, C., Reus, M., and Holzwarth, A. R. (2013). Two different mechanisms cooperate in the desiccation-induced excited state quenching in parmelia lichen. J. Phys. Chem. B 117, 11326-11336. doi: 10.1021/jp402881f

Sokolove, P. M., and Marsho, T. V. (1979). Effect of valinomycin on electron-transport in intact spinach-chloroplasts. FEBS Lett. 100, 179-184. doi: 10.1016/0014-5793(79)81159-X

Staehelin, L. A., and Arntzen, C. J. (1983). Regulation of chloroplast membranefunction - protein-phosphorylation changes the spatial-organization of membrane-components. J. Cell Biol. 97, 1327-1337. doi: 10.1083/jcb.97.5.1327

Stirbet, A., and Govindjee (2012). Chlorophyll a fluorescence induction: a personal perspective of the thermal phase, the J-I-P rise. Photosyn. Res. 113, 15-61. doi: $10.1007 /$ s11120-012-9754-5

Stoitchkova, K., Busheva, M., Apostolova, E., and Andreeva, A. (2006). Changes in the energy distribution in mutant thylakoid membranes of pea with modified pigment content. II. Changes due to magnesium ions concentration. J. Photochem. Photobiol B Biol. 83, 11-20. doi: 10.1016/j.jphotobiol.2005.11.011

Strasser, R. J., Srivastava, A., and Govindjee (1995). Polyphasic chlorophyll a fluorescence transient in plants and cyanobacteria. Photochem. Photobiol. 61, 32-42. doi: 10.1111/j.1751-1097.1995.tb09240.x

Stys, D. (1995). Stacking and separation of photosystem I and photosystem II in plant thylakoid membranes: a physico-chemical view. Physiol. Plant. 95, 651-657. doi: 10.1111/j.1399-3054.1995.tb05535.x

Telfer, A., Allen, J. F., Barber, J., and Bennett, J. (1983). Thylakoid protein-phosphorylation during state-1-state-2 transitions in osmotically shocked pea-chloroplasts. Biochim. Biophys. Acta 722, 176-181. doi: 10.1016/0005-2728(83)90171-8

Tester, M., and Blatt, M. R. (1989). Direct measurement of K+ channels in thylakoid membranes by incorporation of vesicles into planar lipid bilayers. Plant Physiol. 91, 249-252. doi: 10.1104/pp.91.1.249

Tikhonov, A. N. (2013). pH-Dependent regulation of electron transport and ATP synthesis in chloroplasts. Photosyn. Res. 116, 511-534. doi: $10.1007 /$ s11120-013-9845-y

Tikkanen, M., and Aro, E.-M. (2012). Thylakoid protein phosphorylation in dynamic regulation of photosystem II in higher plants. Biochim. Biophys. Acta Bioenerg. 1817, 232-238. doi: 10.1016/j.bbabio.2011.05.005

Tikkanen, M., Nurmi, M., Kangasjarvi, S., and Aro, E. M. (2008). Core protein phosphorylation facilitates the repair of photodamaged photosystem II at high light. Biochim. Biophys. Acta Bioenerg. 1777, 1432-1437. doi: 10.1016/j.bbabio.2008.08.004

Tsiavos, T., Ioannidis, N. E., and Kotzabasis, K. (2012). Polyamines induce aggregation of LHC II and quenching of fluorescence in vitro. Biochim. Biophys. Acta 1817, 735-743. doi: 10.1016/j.bbabio.2012.01.007

Unlu, C., Drop, B., Croce, R., and Van Amerongen, H. (2014). State transitions in Chlamydomonas reinhardtii strongly modulate the functional size of photosystem II but not of photosystem I. Proc. Natl. Acad. Sci. U.S.A. 111, 3460-3465. doi: 10.1073/pnas.1319164111

Vambutas, V., Beattie, D. S., and Bittman, R. (1984). Isolation of protein(s) containing chloride ion transport activity from thylakoid membranes. Arch. Biochem. Biophys. 232, 538-548. doi: 10.1016/0003-9861(84)90571-X

Vambutas, V., and Schechter, S. (1983). Chloride ion transport and its inhibition in thylakoid membranes. Arch. Biochem. Biophys. 224, 442-448. doi: 10.1016/0003-9861(83)90230-8

Vambutas, V., Tamir, H., and Beattie, D. S. (1994). Isolation and partial characterization of calcium-activated chloride ion channels from thylakoids. Arch. Biochem. Biophys. 312, 401-406. doi: 10.1006/abbi.1994.1325
Vandermeulen, D. L., and Govindjee (1974). Relation of membrane structuralchanges to energy spillover in oat and spinach-chloroplasts - use of fluorescence probes and light-scattering. Biochim. Biophys. Acta 368, 61-70. doi: 10.1016/0005-2728(74)90097-8

Varkonyi, Z., Nagy, G., Lambrev, P., Kiss, A. Z., Szekely, N., Rosta, L., et al. (2009). Effect of phosphorylation on the thermal and light stability of the thylakoid membranes. Photosyn. Res. 99, 161-171. doi: 10.1007/s11120-008-9386-y

Vener, A. V. (2007). Environmentally modulated phosphorylation and dynamics of proteins in photosynthetic membranes. Biochim. Biophys. Acta Bioenerg. 1767, 449-457. doi: 10.1016/j.bbabio.2006.11.007

Vener, A. V., Harms, A., Sussman, M. R., and Vierstra, R. D. (2001). Mass spectrometric resolution of reversible protein phosphorylation in photosynthetic membranes of Arabidopsis thaliana. J. Biol. Chem. 276, 6959-6966. doi: 10.1074/jbc.M009394200

Vredenberg, W., Durchan, M., and Prasil, O. (2009). Photochemical and photoelectrochemical quenching of chlorophyll fluorescence in photosystem II. Biochim. Biophys. Acta Bioenerg. 1787, 1468-1478. doi: 10.1016/j.bbabio.2009.06.008

Vredenberg, W., Durchan, M., and Prášil, O. (2012). The analysis of PS II photochemical activity using single and multi-turnover excitations. J. Photochem. Photobiol. B 107, 45-54. doi: 10.1016/j.jphotobiol.2011. 11.009

Vredenberg, W. J., and Bulychev, A. A. (2002). Photo-electrochemical control of photosystem II chlorophyll fluorescence in vivo. Bioelectrochemistry 57, 123-128. doi: 10.1016/S1567-5394(02)00062-2

Walters, R. G., Ruban, A. V., and Horton, P. (1996). Identification of proton-active residues in a higher plant light-harvesting complex. Proc. Natl. Acad. Sci. U.S.A. 93, 14204-14209. doi: 10.1073/pnas.93.24.14204

Walz, D., Schuldin, S., and Avron, M. (1971). Photoreactions of chloroplasts in a glycine medium. Eur. J. Biochem. 22, 439-444. doi: 10.1111/j.1432-1033.1971.tb01562.x

Wollman, F. A., and Diner, B. A. (1980). Cation control of fluorescence emission, light scatter, and membrane stacking in pigment mutants of Chlamydomonas Reinhardii. Arch. Biochem. Biophys. 201, 646-659. doi: 10.1016/0003-9861(80)90555-X

Wong, D., and Govindjee (1979). Antagonistic effects of mono-valent and divalent-cations on polarization of chlorophyll fluorescence in thylakoids and changes in excitation-energy transfer. FEBS Lett. 97, 373-377. doi: 10.1016/0014-5793(79)80124-6

Wong, D., Merkelo, H., and Govindjee (1979). Regulation of excitation transfer by cations - wavelength-resolved fluorescence lifetimes and intensities at 77 $\mathrm{k}$ in thylakoid membranes of pea-chloroplasts. FEBS Lett. 104, 223-226. doi: 10.1016/0014-5793(79)80819-4

Wraight, C. A., and Crofts, A. R. (1970). Energy-dependent quenching of chlorophyll-a fluorescence in isolated chloroplasts. Eur. J. Biochem. 17, 319-327. doi: 10.1111/j.1432-1033.1970.tb01169.x

Xiao, F. G., Ji, H. F., and Shen, L. (2012). Insights into the region responding to Delta $\mathrm{pH}$ change in major light harvesting complex. J. Photochem. Photobiol. B Biol. 111, 35-38. doi: 10.1016/j.jphotobiol.2012.03.007

Xu, H. X., Martinoia, E., and Szabo, I. (2015). Organellar channels and transporters Cell Calcium 58, 1-10. doi: 10.1016/j.ceca.2015.02.006

Yamakawa, H., Fukushima, Y., Itoh, S., and Heber, U. (2012). Three different mechanisms of energy dissipation of a desiccation-tolerant moss serve one common purpose: to protect reaction centres against photo-oxidation. J. Exp. Bot. 63, 3765-3775. doi: 10.1093/jxb/ers062

Zaks, J., Amarnath, K., Sylak-Glassman, E. J., and Fleming, G. R. (2013). Models and measurements of energy-dependent quenching. Photosyn. Res. 116, 389-409. doi: 10.1007/s11120-013-9857-7

Conflict of Interest Statement: The authors declare that the research was conducted in the absence of any commercial or financial relationships that could be construed as a potential conflict of interest.

Copyright (C) 2016 Kaña and Govindjee. This is an open-access article distributed under the terms of the Creative Commons Attribution License (CC BY). The use, distribution or reproduction in other forums is permitted, provided the original author(s) or licensor are credited and that the original publication in this journal is cited, in accordance with accepted academic practice. No use, distribution or reproduction is permitted which does not comply with these terms. 